\title{
AP2 regulates Thickveins trafficking through Rab11 to attenuate NMJ growth signaling in
}

\section{Drosophila}

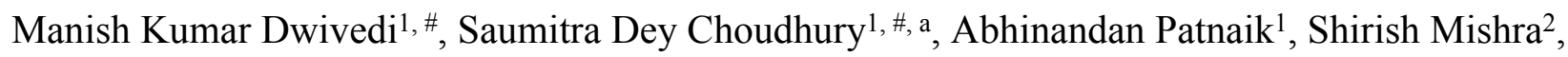
Raghu Padinjat ${ }^{2}$ and Vimlesh Kumar ${ }^{1, *}$

${ }^{1}$ Department of Biological Sciences, Indian Institute of Science Education and Research (IISER) Bhopal, Academic Building 3, Bhauri, Bhopal-462 066, Madhya Pradesh, India.

${ }^{2}$ National Centre for Biological Sciences, Bellary Road, Bangalore-560065, Karnataka, India.

a Present address: Section on Cellular Communication, National Institute of Child Health and Human Development, National Institutes of Health, 35 Convent Drive, Bethesda, MD 20892, USA.

\# Equal contribution

* Author for correspondence

Corresponding author: Phone - 00917552691405

Fax - 00917552692392

Email-vimlesh@iiserb.ac.in

Running title: Regulation of synaptic growth signaling by $\sigma 2$-adaptin

Keywords: $\sigma 2$-adaptin; BMP-receptors; Thickveins; Rab11; Growth signaling 


\begin{abstract}
Compromised endocytosis in neurons leads to synapse overgrowth and altered organization of synaptic proteins. However, the molecular players and the signaling pathways which regulate the process remains poorly understood. Here we show that $\sigma 2$-adaptin, one of the subunits of the AP2complex, genetically interacts with BMP type I receptor, Thickveins (Tkv), and Daughter against decapentaplegic (Dad), two of the components of BMP signaling. We found that mutations in $\sigma 2-$ adaptin lead to an accumulation of Tkv receptors at the $\mathrm{NMJ}$ and results in a significant reduction in Tkv-positive early endosomes in the presynaptic terminals. Interestingly, the level of small GTPase Rab11 was significantly reduced in the $\sigma 2$-adaptin mutant synapses. Consistent with the role of $\sigma 2$-adaptin and Rab11 in the regulation of the same signaling pathway, a mutation in Rab11 or overexpression of a GDP-locked form of Rab11 (Rab11 ${ }^{\mathrm{S} 25 \mathrm{~N}}$ ) phenocopies the morphological and signaling defects of the $\sigma 2$-adaptin mutants. Finally, we demonstrate that $\sigma 2$-adaptin mutants show an accumulation of large vesicles and massive membranous structures, akin to endosomes at the synapse. Thus, we propose a model in which AP2 regulates $\mathrm{Tkv}$ internalization and recycling through a process that requires Rab11 activity to control the synaptic growth.
\end{abstract}




\section{INTRODUCTION}

Synapse development and refinement is an interplay of signaling networks mediated by various endocytic, cytoskeletal, and actin regulatory proteins, Ubiquitin-Proteasome mediated protein degradation, Bone morphogenetic protein (BMP), and wingless (Wnt) pathways [1-8]. Understanding the crosstalk amongst them is crucial to our understanding of this process that regulate synapse development, refinement and plasticity [9]. BMP signaling pathway is a wellstudied growth-promoting pathway at the Drosophila NMJ synapses $[1,7,10,11]$. The canonical BMP signaling is dependent on phosphorylated Smad (pMAD in Drosophila) and its translocation in the ventral ganglion nuclei followed by the transcription of BMP target genes. At the Drosophila NMJ, the retrograde bone morphogenetic protein (BMP) signaling is initiated by secretion of glass bottom boat (Gbb) from the postsynaptic muscle. Gbb binds to wishful thinking (Wit, a type II receptor) and thickveins and saxophone (Tkv and Sax, type I receptors) at the presynaptic nerve terminals to control NMJ growth and function [7, 10, 12]. Gbb binding to Wit triggers the tetramerization of BMP receptors that, in turn, phosphorylates the Smad transcription factor, mothers against decapentaplegic (Mad). The phosphorylated form of Mad (pMAD) in complex with the co-Smad Medea is then retrogradely transported to the motor neuron nuclei, where it regulates gene transcription $[13,14]$.

Multiple studies have shown a tight correlation between defective endocytosis, altered synapse growth, and elevated synaptic phospho-MAD levels, which indicates increased BMP signaling $[1,8,11,15,16]$. One such study has shown that Nwk, an F-BAR and SH3 domaincontaining protein that negatively regulates synaptic growth, interacts with Tkv along with Dap160 and Dynamin (both endocytic proteins) to attenuate retrograde BMP signaling during NMJ growth [11]. Endocytic and endosomal pathways are, therefore, critical to controlling both the activity and localization of signaling proteins that regulate synaptic growth [17, 18]. Clathrin-mediated endocytosis (CME) is required not only for basal synaptic transmission at nerve terminals but also 
for peripheral synapse development [3, 19, 20]. For instance, perturbations in CME resulting from mutations in Dynamin, AP2 subunits, Endo, or Synj all exhibit NMJ structural defects resulting in increased number but decreased size of synaptic boutons in Drosophila [3, 20]. Defects in intracellular trafficking can also lead to enhanced signaling from the cellular compartments (like endosomes) that has implications on synapse development [17, 21-23]. In the neuronal context, the efficacy of intercellular signaling is regulated by the trafficking of activated receptor/ligand complexes following endocytosis from the presynaptic membrane.

Tightly regulated endocytic transport of BMP receptors relies on the spatiotemporal regulation of Rab GTPase function [24]. The Rab-family of GTPases regulates the progression of receptor endocytosis and participates in the successive steps of membrane maturation, receptor transport, and turnover [25]. In particular, Rab5 regulates vesicle formation and is associated with early endosomes, while Rab7 and Rab11 associate with late and recycling endosomes, respectively $[26,27]$. Endosomal trafficking of BMP signaling complexes at the nerve terminals is known to fine-tune the intensity and persistence of BMP signaling [9, 18]. Altered distribution or misregulation of Rab11 has been shown to suppress Tkv trafficking from early endosome to presynaptic membrane resulting in elevated BMP signaling [9, 11, 28, 29]. An important, yet enigmatic question, is the correlation between defective CME and aberrant synaptic growth. For instance, it is not known whether specific modes of endocytosis internalize specific cargos whose trafficking defect perturbs synaptic signaling. Similarly, it is unclear whether the NMJ structural defects associated with the endocytic mutants is a consequence of deficient endosomal trafficking leading to aberrant synaptic signaling. It is likely that perturbing CME deregulates signaling modules of BMP pathway that leads to elevated pMAD in the endocytic mutants $[3,11]$.

In central synapses, AP2-dependent CME is dispensable for membrane regeneration from the presynaptic plasma membrane following high-frequency nerve stimulation [30]; the critical role of $\mathrm{CME}$ in generating vesicles from endosome-like structures following bulk 
membrane endocytosis cannot be ruled out [31]. Previous studies support a model in which compromised CME can lead to defective signalosome trafficking by trapping signaling molecules in endosomes or intermediate structures of the endosomal pathway [22, 23, 32-35]. A recent study has highlighted the role of BMP receptor macropinocytosis to restrain BMP-mediated synaptic development by linking Abl and Rac1 GTPase signaling, indicating fine-tuning of endosomal trafficking of BMP receptors by small GTPases [36].

Our previous study has shown elevated levels of synaptic as well as motor-nuclei pMAD in $\sigma 2$-adaptin mutants [3]. In order to investigate the underlying signaling mechanisms leading to elevated pMAD levels, we performed epistatic interactions between $\sigma 2$-adaptin mutants with the components of BMP signaling. Our studies show that $\sigma 2$-adaptin is required for internalization and endosomal trafficking of the BMP receptor Tkv at the NMJ synapses. Analysis of endocytic trafficking using endosomal markers suggests that defective Tkv receptor trafficking in $\sigma 2$-adaptin mutants is a consequence of reduced synaptic Rab11 levels. Finally, our ultrastructural analysis of NMJ reveals the accumulation of large vesicles and supports a role of $\sigma 2$-adaptin in the generation of signalosomes containing vesicles, possibly from endosomal structures. Thus, our studies reveal a novel function of $\sigma 2$-adaptin in attenuating BMP-signaling by facilitating trafficking and recycling of the Tkv receptor through Rab11 containing recycling-endosomes.

\section{RESULTS}

\section{o2-adaptin genetically interacts with regulators of BMP signaling}

In a previous study, we have shown that mutations in o2-adaptin cause an increase in bouton numbers at NMJ as well as upregulation of pMAD, an effector of the BMP pathway [3]. To explore the role $\sigma 2$-adaptin in regulating BMP signaling at the NMJ, we first assessed the epistatic interaction between $\sigma 2$-adaptin and components of the BMP-signaling pathway. We found that introducing one mutant copy of the BMP type I receptor, Thickveins (Tkv) or co-Smad, Medea in 
o2-adaptin mutant background could significantly suppress the synaptic overgrowth phenotype in these animals (Figure 1A-E). The number of boutons was significantly rescued in $t k v^{7} /+$;

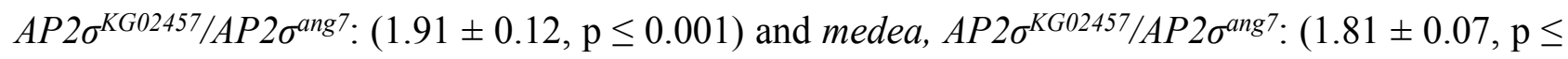
$0.001)$ when compared to $A P 2 \sigma^{K G 02457 / A P 2 \sigma^{a n g 7}}(2.85 \pm 0.08, \mathrm{p} \leq 0.001)$. However, there was no

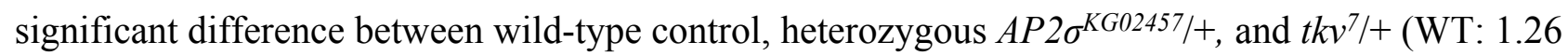
$\pm 0.06, A P 2 \sigma^{K G 02457 /+:} 1.33 \pm 0.03$ and $t k v^{7} /+: 1.34 \pm 0.05$ ) (Figure $1 \mathrm{~F}$ ).

Consistent with the above observations, we found that mutating one copy of the type II BMP receptor, wit could also significantly rescue the synaptic overgrowth phenotype in $\sigma 2$-adaptin mutants, $\left(\right.$ wit $^{A 12}, A P 2 \sigma^{K G 02457} / A P 2 \sigma^{a n g 7}: 2.00 \pm 0.08$ vs. $A P 2 \sigma^{K G 02457} / A P 2 \sigma^{a n g 7}: 2.50 \pm 0.11 ; \mathrm{p} \leq$ 0.01) (Figure S1). Since elevated BMP signaling results in the formation of smaller boutons, we quantified the bouton area in these genotypes. We found that introducing one copy of $t k v^{7}\left(t k v^{7} /+\right.$;

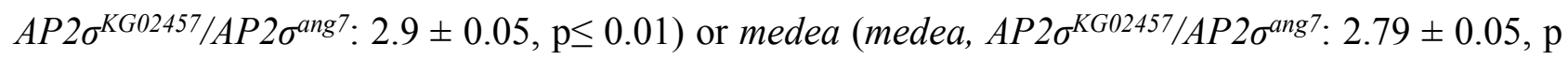
$\leq 0.05$ ) in $\sigma 2$-adaptin mutant background slightly but significantly rescued the bouton area when compared to $\sigma 2$-adaptin mutant alone $\left(A P 2 \sigma^{K G 02457} / A P 2 \sigma^{a n g 7}: 1.97 \pm 0.02\right)$ (Figure $\left.1 \mathrm{G}\right)$. We found that partially downregulating these BMP pathway molecules reduces the clustering of boutons at the mutant NMJ (Figure 1 $\mathrm{A}^{\prime}-1 \mathrm{E}^{\prime}$ ). Thus, our data suggest that $\sigma 2$-adaptin genetically interacts with the BMP receptors to regulate NMJ morphology.

In order to assess whether elevated BMP signaling indeed was responsible for the neuronal overgrowth in $\sigma 2$-adaptin mutant, we tested the interaction between $\sigma 2$-adaptin and the inhibitory Smad, Daughters against decapentaplegic (Dad), a negative regulator of BMP signaling $[11,37]$. Phosphorylated MAD (pMAD) interacts with the co-Smad, Medea, and gets translocated to the nucleus to activate BMP target genes. Dad competes with Medea for binding with pMAD, which prevents its translocation into the nucleus and inhibits the relay of BMP signal [38]. dad loss-of-function mutant shows neuronal overgrowth with an increased number of satellite boutons, a phenotype that is strikingly similar to the endocytic mutants $[11,15]$. We examined the total 
number of synaptic boutons in transheterozygotes of o2-adaptin and dad mutants (Figure 2A-D). While the number of boutons in larvae heterozygous for $\sigma 2$-adaptin $A P 2 \sigma^{K G 02457 /+}(1.23 \pm 0.05)$ and $\mathrm{dad}, \mathrm{dad}^{\mathrm{iE} 4 /+}(1.39 \pm 0.09)$ was comparable with wild-type control $(1.26 \pm 0.06)$, transheterozygous $\mathrm{dadi}^{1 E 4} / A P 2 \sigma^{K G 02457}(1.89 \pm 0.09, \mathrm{p} \leq 0.001)$ showed significantly higher bouton number when compared to controls (Figure 2E). Taken together, our data indicate that $\sigma 2$-adaptin may regulate BMP signaling at the Drosophila NMJ.

\section{The functional and morphological aspect of $\sigma 2$-adaptin can be genetically delineated}

Since one mutant copy of the Tkv receptor in the o2-adaptin mutant background significantly restores the morphological defects, we asked whether the electrophysiological defects associated with the $\sigma 2$-adaptin mutant are also rescued. We measured evoked excitatory junction potential (EJP), quantal content (QC), and high-frequency intracellular recording on wild-type,

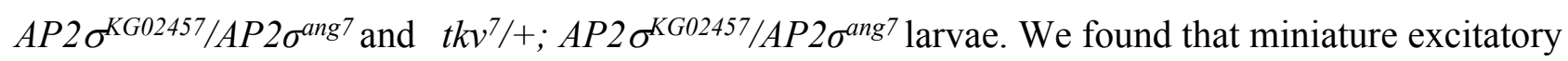
junction potential (mEJP) amplitude and frequency, EJP amplitude, or the activity-dependent decline in the EJP amplitude in $t k v^{7} /+; A P 2 \sigma^{K G 02457} / A P 2 \sigma^{a n g 7}$ larvae were not significantly different than the $\sigma 2$-adaptin mutant (Figure 3A-C). Moreover, we found that $t k v^{7} /+; A P 2 \sigma^{K G 02457 / A P 2 \sigma^{a n g} 7}$ animals do not show a significant change in the quantal content compared to the o2-adaptin mutants $\left(t k v^{7} /+; A P 2 \sigma^{K G 02457} / A P 2 \sigma^{a n g 7}, \mathrm{QC}=38.20 \pm 3.09\right.$ vs. $A P 2 \sigma^{K G 02457} / A P 2 \sigma^{a n g 7}, \mathrm{QC}=39.29 \pm$ 5.81) (Figure 3D). These data suggest that while reducing the level of BMP signaling by lowering Tkv receptors in $\sigma 2$-adaptin mutant partially rescues the morphological defects, it does not restore the physiological deficiencies in $\sigma 2$-adaptin mutants suggesting that functional and morphological defects in 62-adaptin mutant are independent of one another.

\section{Loss of $\sigma 2$-adaptin leads to the accumulation of endosome-like structures at the NMJ}

Studies have shown that CME and Rab11 mediate the internalization and recycling of the BMP receptors $[28,39]$. Altered levels of endosomal proteins such as Rab5 and Rab11 that are 
known to be involved in the trafficking of BMP receptors result in elevated BMP signaling leading to an increase in the number of boutons. We performed the NMJ transmission electron microscopy to understand how the loss of $\sigma 2$-adaptin affects synapse ultrastructure. Interestingly, ultrastructural analysis of $\sigma 2$-adaptin deficient synapses showed an accumulation of large endosome-like structures, similar to what has been shown in mutants that affect the endocytic and endosomal recycling machinery such as clathrin [40, 41], AP180 [42], Rab5 [43], Rab8 [44] and Rab11 [45]. We found a drastic decrease in the SV density ( $w^{1118}: 85.18 \pm 12.26$ vs. AP2 $\sigma^{K G 02457}$ / $\left.A P 2 \sigma^{\text {ang7: }} 28.02 \pm 14, \mathrm{p} \leq 0.01\right)$ and an increase in the size of SVs $\left(w^{1118}: 43.16 \pm 0.94\right.$ vs. $A P 2 \sigma^{\left.K G 02457 / A P 2 \sigma^{a n g 7}: 71.53 \pm 3.7, \mathrm{p} \leq 0.001\right)}$ in the $\sigma 2$-adaptin mutants. Moreover, we found large membrane invaginations in the mutant synapse, similar to what has been reported earlier for clathrin mutants [41]. These ultrastructural defects were rescued upon ubiquitous expression of a б2-adaptin transgene (actin5C/+; AP2 $\sigma^{K G 02457}, U A S-A P 2 \sigma / A P 2 \sigma^{a n g 7}: \mathrm{SV}$ density $(107.9 \pm 11.32)$ and size $(43.1 \pm 1.46)$ (Figure 4A-E). Together, our data indicate that compromised regeneration of vesicles from the presynaptic membrane and defective membrane recycling in $\sigma 2$-adaptin mutants results in the accumulation of large endosome-like structures.

\section{o2-adaptin mutants have increased synaptic Tkv receptors}

AP2 complex has been shown to regulate CME and activity-dependent vesicle regeneration from endosome-like vacuoles $[30,46]$. Because ultrastructural analysis of $\sigma 2$-adaptin mutants revealed accumulation of membrane invaginations and large endosome-like structures similar to mutants with perturbed endosomal trafficking such as Rab5, Rab11 and, Rab8 mutants [43-45], we hypothesized that o2-adaptin could be involved either in endocytosis of BMP receptors from the presynaptic membrane or in the endosome-dependent trafficking of the receptors. To check this possibility, we first assessed the level of Tkv receptors at the larval NMJ. Since a specific antibody against Tkv receptors is not available, we expressed an EGFP-tagged Tkv receptor transgene in the motor neurons of o2-adaptin mutants (D42-Gal4>UAS-Tkv-EGFP; 
$\left.A P 2 \sigma^{a n g 7} / A P 2 \sigma_{-}{ }^{K G 02457}\right)$. Interestingly, we found a significant accumulation of Tkv receptors at $\sigma 2-$ adaptin synapses (D42-Gal4, AP2 $\left.\sigma^{K G 02457} / A P 2 \sigma^{a n g 7}, U A S-T k v-E G F P: 135 \pm 6.7, \mathrm{p} \leq 0.01\right)$ when compared to control (D42-Gal4/UAS-Tkv-EGFP: $100 \pm 9.36)$ (Figure 5A-E). This synaptic accumulation of Tkv-EGFP could be due to compromised endocytosis from the plasma membrane. To check this possibility, we analyzed the intensity profiles of $\mathrm{Tkv}$ receptor and the presynaptic membrane maker, HRP. When compared to the control synapses where Tkv localizes both at the presynaptic membrane as well as within the bouton, we found a higher intensity peak of Tkv-EGFP at the synaptic membrane of $\sigma 2$-adaptin mutant (Figure 5F-K). Taken together, these data suggest endocytosis/trafficking of Tkv receptors in $\sigma 2$-adaptin mutants are severely compromised, leading to its accumulation at the synaptic membranes.

\section{б2-adaptin mutation results in decreased levels of recycling endosomal marker Rab11}

Receptors are known to be endocytosed, trafficked to the early endosomes, and sorted out for recycling or degradation [47-49]. Therefore, we hypothesized that the endocytosis of Tkv receptors from the presynaptic membrane should be compromised in the $\sigma 2$-adaptin mutant. To test this prediction, we measured overall Tkv receptor levels at NMJ in $\sigma 2$-adaptin mutants using TkvEGFP. We found a significant increase of Tkv receptors at NMJ in $\sigma 2$-adaptin mutants. Further, we assessed the colocalization of Tkv-EGFP with an early endosomal marker, Rab5, at the NMJ. We found a drastic decrease in colocalization between Rab5 and Tkv-EGFP in $\sigma 2$-adaptin mutant (D42-Gal4, AP2 $\left.\sigma^{K G 02457 / A P 2 \sigma^{a n g} 7, U A S-T k v-E G F P:} 27.40 \pm 3.82, \mathrm{p} \leq 0.001\right)$ when compared to control (D42-Gal4/UAS-Tkv-EGFP: $65.74 \pm 3.75$ ) (Figure 6A-G). Similar results were obtained when the same images were used to quantify the extent of colocalization using motion tracker software $[50,51]$. Defective endosomal recycling results in the enrichment of activated receptors in early endosomes that cause an elevation in BMP signaling [28, 44, 52]. Enriched Tkv receptor levels at the synaptic membrane and its decreased colocalization with Rab5 in 62 -adaptin mutant suggests compromised internalization of Tkv receptor. 
The decreased colocalization of Tkv with Rab5 could also be due to a reduced level of Rab5 itself in $\sigma 2$-adaptin mutants. To test this possibility, we quantified the levels of synaptic Rab5 at the mutant synapses. We found that the synaptic levels of the early endosomal marker, Rab5 $\left(w^{1118}: 100.0 \pm 3.0\right.$ vs. $\left.A P 2 \sigma^{K G 02457} / A P 2 \sigma^{a n g 7}: 97.25 \pm 4.81\right)$ or late endosomal marker, Rab7 ( $w^{1118}$ : $100.0 \pm 5.71$ vs. $\left.A P 2 \sigma^{K G 02457} / A P 2 \sigma^{a n g 7}: 115.6 \pm 8.17\right)$ were not altered in $\sigma 2$-adaptin mutant (Figure 6H-N and Supplemental Figure S2). These results suggest that decreased colocalization between Tkv-EGFP and Rab5 is primarily due to compromised internalization of Tkv receptors from the presynaptic membrane.

Synaptic proteins such as Nwk have been shown to associate with Rab11 and regulates BMP receptor recycling. Moreover, mutants that affect the recycling of BMP receptors show elevated pMAD levels and an increased number of boutons [11, 28, 53]. This prompted us to assess any possible defects in the recycling endosomes in $\sigma 2$-adaptin mutants. In order to test the defect in recycling endosome trafficking, we stained NMJs with recycling endosome marker Rab11. Interestingly, we observed a drastic reduction in synaptic Rab11 levels ( $w^{1118}: 100.0 \pm 5.73$ vs. $A P 2 \sigma^{\left.K G 02457 / A P 2 \sigma^{a n g 7}: 61.81 \pm 7.10, \mathrm{p} \leq 0.001\right)}$ in $\sigma 2$-adaptin mutant. (Figure 7A-I). Synaptic Rab11 levels were restored to control levels upon neuronal expression of a $\sigma 2$-adaptin transgene in

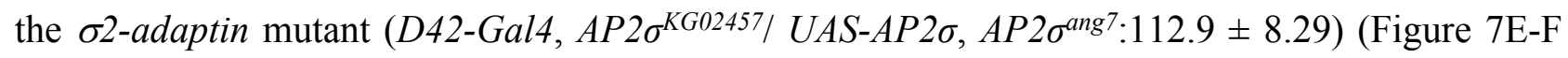
and 7I). Consistent with these results, we found that downregulation of other AP2 subunits i.e. $\alpha$ adaptin (D42-Gal4> $\quad \alpha$-adaptin $\left.{ }^{\mathrm{RNAi}}: 65.4 \quad \pm 3.31, \quad \mathrm{p} \leq 0.001\right) ; \quad \beta_{2}$-adaptin $\quad\left(\right.$ D42-Gal4> $\quad \beta_{2^{-}}$ $\left.\operatorname{adaptin}^{\text {RNAi:}} 75.63 \pm 2.55, \mathrm{p} \leq 0.001\right)$ and $\mu_{2}$-adaptin $\left(D 42-\right.$ Gal4 $>\mu_{2}$-adaptin ${ }^{\text {RNAi: }}: 78.30 \pm 4.5$, $\mathrm{p} \leq 0.001$ ) in the motor neurons results in a significant decrease in Rab11 levels when compared with controls $\left(w^{1118}: 100 \pm 3.15\right)$ (Supplemental Figure S3). Taken together, these data indicate that: a) AP2 complex regulates recycling endosomes, and b) compromised endocytosis and defective recycling of the endocytosed $\mathrm{Tkv}$ receptors results in accumulation of $\mathrm{Tkv}$ receptors at the presynaptic membrane. 


\section{Rab11 mutants phenocopy the NMJ and BMP-signaling defects of $\sigma 2$-adaptin mutants}

Previous studies have shown that mutations in Rab11 results in NMJ morphological defects in Drosophila [28, 52]. Since $\sigma 2$-adaptin functions in neurons to regulate BMP-signaling, we next asked if altering the levels of Rab11 specifically in neurons could phenocopy 62 -adaptin mutants and alter BMP signaling. Interestingly, we found that neuronal expression of a dominantnegative form of Rab11 ( $R a b 11^{S 25 N}$ ) phenocopies the NMJ morphological defects of $\sigma 2$-adaptin mutations and shows NMJ overgrowth ( $\left.w^{1118}: 1.56 \pm 0.06\right),($ Rab11 ex2/93Bi $: 2.77 \pm 0.11, \mathrm{p} \leq 0.001)$, $\left(U A S-Y F P-R a b 11^{S 25 N} /+; D 42-G a l 4 /+: 2.26 \pm 0.08, \mathrm{p} \leq 0.001\right)$ and $\left(A P 2 \sigma^{K G 02457 / A P 2 \sigma^{a n g 7}: 2.83 \pm}\right.$ $0.12, \mathrm{p} \leq 0.001$ ) (Figure 8A-D and 8Q). Expressing wild type or constitutively active form of Rab11 does not alter the synaptic morphology (Supplemental Figure S4). Consistent with its role in BMP signaling and NMJ growth, Rab11 mutants as well as animals expressing a dominant-negative form of Rab11 in motor neurons resulted in the accumulation of pMAD at the NMJ synapses $\left(w^{1118}: 100\right.$

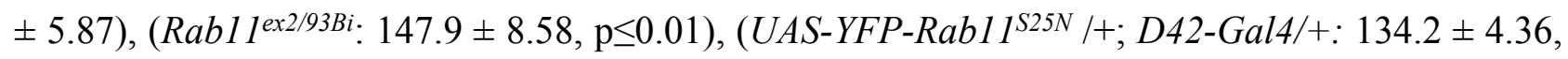

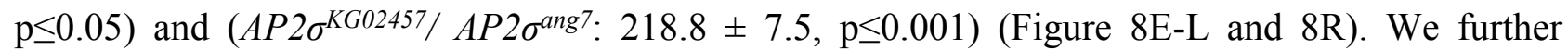
assessed Tkv-EGFP levels at the Rab11 mutant synapses and found that Rab11 mutants show increased Tkv levels at the synapse (D42-Gal4, Rab11 ex2/ Tkv-EGFP, Rab11 ${ }^{93 B i}: 189.5 \pm 10.57$ ) compared to control (D42-Gal4/Tkv-EGFP: $100 \pm 8.71)$ (Figure 8M-P and 8S). This suggests that defective recycling of Tkv in Rab11 mutant results in its accumulation at the synapse leading to increased BMP signaling and synaptic overgrowth. Interestingly, we also found that similar to $\sigma 2$ adaptin mutants, downregulating neuronal levels of $\alpha$-adaptin leads to reduced Rab11 and shows enrichment of pMAD ( $\left.\mathrm{w}^{1118}: 100 \pm 6.66\right),\left(D 42-\right.$ Gal4 $>\alpha$-adaptin $\left.{ }^{\text {RNAi }}: 278.7 \pm 14.51, \mathrm{p} \leq 0.001\right)$ and synaptic overgrowth $\left(\mathrm{w}^{1118}: 1.35 \pm 0.064\right),\left(\right.$ D42-Gal4 $>\alpha$-adaptin $\left.{ }^{\mathrm{RNAi}}: 2.59 \pm 0.12, \mathrm{p} \leq 0.001\right)$ at the Drosophila NMJ (Supplemental Figure S5). Taken together, these data suggest that Rab11- 
dependent trafficking of $\mathrm{Tkv}$ is deregulated in o2-adaptin mutants leading to increased BMP signaling and synaptic overgrowth.

\section{DISCUSSION}

High fidelity neurotransmission depends on the proper endocytosis of synaptic vesicles after their fusion with the pre-synaptic membrane. Defects in endocytosis not only perturb synaptic transmission but also have been implicated in deregulated synaptic growth $[3,16,54,55]$. The striking growth defects at the NMJ in endo, synj and o2-adaptin mutants [3, 54-56] are a consequence of perturbing the endocytic machinery. However, our study on o2-adaptin showed no change in levels of endocytic proteins like Endo, Synj, and Dynamin [8]. Therefore, we sought to address the role of CME in synaptic growth signaling. Defects in endocytosis, in general, have been linked to the BMP signaling cascade that drives the expression of growth-promoting genes through the activity of pMad $[1,8,11,15,16]$. The signaling activity, many a time, is dependent on intracellular traffic that is in part dependent on endocytosis of activated receptors, ultimately impinging on signaling pathways, particularly the BMP, JNK, and Wingless pathways $[1,4,7,8$, $15,57]$. Here, we show for the first time a genetic interaction between $\sigma 2$-adaptin and BMP pathway components. We further provide compelling evidence that the synaptic overgrowth phenotype in o2-adaptin mutant is due to defective Rab11-mediated trafficking of type I BMP receptor, Thickveins.

\section{б2-adaptin interacts with BMP pathway components to regulate neuronal BMP signaling} pathway

Increasing evidence suggest the role of endocytosis in the regulation of synaptic signaling and NMJ growth. Endosomal trafficking of BMP receptors is a crucial regulatory feature that governs synaptic growth. Various proteins are known to interact with BMP receptors and either facilitate or impede the signaling cascade. A recent study in cultured mammalian cells reports one such protein, Angiomotin130 (AMOT130), with a coiled-coil motif and a C-terminal PDZ motif 
that interacts with the BMP receptor BMPR2 and facilitates BMP-SMAD signaling. AMOT130 localizes to endosomes and is thought to modulate GTPase signaling [58]. Endocytic proteins appear to be fascinating candidates as BMP receptor interactors.

Interestingly, Drosophila loss-of-function endocytic mutants correlate with elevated BMP signaling and neuronal overgrowth phenotype $[9,17,20]$. Consistent with this, we showed increased Tkv levels at the NMJ results in an elevated level of BMP pathway in o2-adaptin mutants. If the BMP pathway is responsible for the synaptic overgrowth in o2-adaptin mutants, then manipulating the levels of BMP signaling components should rescue the NMJ phenotype. In agreement, we show that by partially reducing BMP receptors Tkv, Wit, and cytosolic co-Smad molecule, Medea significantly rescues the phenotype. We further confirmed the interaction between $\sigma 2$-adaptin and BMP signaling by showing that $\sigma 2$-adaptin genetically interacts with the negative regulator of BMP signaling, the inhibitory Smad, Dad. Transheterozygotes of $d a d$ and $\sigma 2$ adaptin mutants have an increased number of boutons compared to heterozygotes of either mutant alone.

\section{б2-adaptin regulates trafficking of type I BMP receptor, Thickveins from the plasma membrane to early endosomes}

BMP signaling has been extensively studied in the context of neuronal growth in which activated type I receptor, Tkv is endocytosed in the form of vesicles and fuse with early endosomes to activate downstream signaling molecules. The signaling is attenuated when these activated receptor-containing vesicles recycle back to the plasma membrane or fuse with lysosomes to be degraded [17, 59]. Trafficking of these receptors into and out of such endosomes provides an additional tier for spatial and temporal modulation of signal transduction. The members of the Rab family of small GTPases regulate various stages of endocytosis [24]. Our immunocytochemistry data show elevated Tkv receptor levels at the synapses and motor neuron soma (data not shown) of o2-adaptin mutants. Besides, levels of Rab11 (known for its role in the recycling of Tkv receptor) 
is reduced by half in $\sigma 2$-adaptin mutant synapses. Interestingly, levels of early and late endosomes marked with Rab5 and Rab7, respectively, remain unaffected at the o2-adaptin mutant synapses with a much-reduced colocalization between Rab5 and Tkv receptor punctae compared to controls. Besides, the intensity profile of Tkv and HRP across the bouton shows that $\sigma 2$-adaptin mutant has a higher intensity of $\mathrm{Tkv}$ at the membrane compared to control, indicating that a significant proportion of the $\mathrm{Tkv}$ receptors are accumulated at the presynaptic membrane

Tkv receptors could be accumulated either at the plasma membrane due to inefficient CME or at the early endosomes caused by inefficient recycling. If Tkv were accumulated at the early endosomes, we would expect greater colocalization with Rab5, which is not the case. However, based on reduced Rab11 staining at the mutant synapses, we conclude that the portion of the receptors that remain in Rab5 positive early endosomes fail to recycle back to the plasma membrane. This conclusion also fits with previous observations that defective CME results in the accumulation of endosome-like structures in cultured hippocampal neurons [30] and is substantiated by our electron microscopy data. The link between clathrin-mediated dynamindependent endocytosis and BMP signaling is still a contentious topic. A recent study using human umbilical vein endothelial cells (HUVECs) has shown that treating these cells with BMP-9 triggered caveolin-1 and dynamin-2 mediated endocytosis of its receptor, activin-like kinase 1 (ALK-1). Surprisingly, this ALK-1 endocytosis was not mediated by Clathrin heavy chain [60]. At the Drosophila NMJ, perturbing endocytosis results in upregulated BMP signaling [11], whereas in Drosophila wing discs and intestinal stem cells, endocytosis facilitates the signaling cascade by internalizing $\operatorname{Tkv}[61,62]$, pointing towards a tissue-specific mechanism. Our results suggest a model where bulk membrane endocytosis is insufficient in removing $\mathrm{Tkv}$ from the plasma membrane; besides, the synapses in $\sigma 2$-adaptin mutants fail to recycle remaining receptors from early endosomes leading to enhanced signaling and drastic NMJ growth defects. 


\section{Functional and morphological aspects of $\sigma 2$-adaptin-mediated BMP signaling can be delineated}

Morphological features of synapses often dictate functional outcomes, and physiological analyses of BMP signaling mutants reveal the same. In BMP type II receptor mutant, wit larvae, the size of the NMJ is greatly reduced with concomitant reduced evoked excitatory potentials [10, 12]. Analyses of BMP type I receptor mutants, $t k v$ and sax, co-Smad medea, and transcription factor mad, all have smaller synapses with severe functional deficits [6]. The same is true for the musclesecreted BMP ligand, Gbb. gbb mutant larvae also exhibit shorter NMJs with severely reduced evoked potentials [7]. o2-adaptin mutant synapses, however, show a modest reduction in evoked potentials, and the protein is dispensable for maintaining basal synaptic transmission [3]. Rundown of EJP amplitudes during high-frequency stimulation is used to measure endocytic defects. Synaptic mutants implicated in CME, such as endophilin, synj and dap160, show a rapid stimulusdependent decline in EJP amplitude that recovers following a period of rest after the highfrequency stimulation paradigm $[19,55]$. In our previous study, we had reported that $\sigma 2-$ adaptin mutants do not recover from synaptic depression even after a period of rest following cessation of high-frequency stimulation [3]. This observation suggested that in addition to its requirement in synaptic membrane retrieval, the $\sigma 2$-adaptin function is also required during the much slower process of SV trafficking, possibly at one of the rate-limiting steps in SV regeneration. This result is now supported by our EM data that shows an accumulation of endosome-like structures at the mutant synapses. EJP and high-frequency recordings from $\sigma 2$ adaptin mutant synapses with one copy of $t k v^{7}$ did not show any rescue in synaptic function. These data drive the conclusion that partial reduction of BMP pathway components can only rescue morphological defects in $\sigma 2$-adaptin mutants but not functional aspects and that morphological and functional deficits can be delineated in these mutants. Besides, a partial rescue of bouton size and 
bouton clustering at the NMJ argues for possible deregulation of multiple signaling pathways in $\sigma 2$-adaptin mutants that remains to be explored.

Our study uncovers and extends the existing knowledge of synaptic growth signaling and endocytosis. We provide four lines of evidence on the critical role of $\sigma 2$-adaptin in modulating BMP-dependent synaptic growth signaling at the Drosophila NMJ. First, we show using genetics that the morphological defects in o2-adaptin mutant synapses can be partially rescued by introducing a mutant copy of the BMP receptors, $t k v$, and wit. We also show a direct epistatic interaction between $\sigma 2$-adaptin and the inhibitory Smad, Dad. Second, using immunohistochemistry, we show that $\sigma 2$-adaptin mutant synapses accumulate Tkv at the plasma membrane and some of these receptors that are endocytosed and make it to the early endosomes fail to recycle back to the plasma membrane due to decreased Rab11 GTPase. Third, our electrophysiology data establish that morphological and functional defects can be delineated in $\sigma 2$ adaptin mutants. Finally, our electron micrographs provide conclusive evidence showing the presence of large endosomes that match with our speculation that $\sigma 2$-adaptin is critically required at a later step of vesicle regeneration following endocytosis from the plasma membrane. Partial rescue of bouton size and bouton clustering argues for possible deregulation of multiple signaling pathways in $\sigma 2$-adaptin mutants.

This study thus opens new avenues where the role of other CME components and their interaction with various growth signaling pathways can be studied. Since receptor localization and regulation appears to be the central theme in modulating BMP signaling and synapse growth, it will be interesting to perform structure-function analysis of BMP receptors and identify key residues/motifs that interact with AP2 and facilitate its endocytosis. Mutating tyrosine-based signal $(\mathrm{YXX} \phi)$ and dileucine-based signal ([DE]XXXL[LI]) motifs in Tkv and Wit could lead to further understanding of these intricate interactions. 


\section{MATERIALS AND METHODS}

\section{Fly stock}

Flies were grown and maintained at $25^{\circ} \mathrm{C}$ temperature in a standard cornmeal medium as described in [3]. The wild type $w^{1118}$ was used as control unless otherwise stated. Genetic combinations and recombinations were made using standard genetic crosses. All the mutants, controls, and rescued larvae were grown under the non-crowded condition on apple agar plates with yeast paste dollop. The following stocks were obtained from Bloomington Drosophila Stock Center (BDSC)- $t k v^{7}$ (BL3242), medea (BL7340), Wit ${ }^{A 12}$ (BL5173), dadilE4 (BL10305), AP2 $\sigma^{K G 02457}$ (BL13478), UAS-Rab11-GFP (BL8506), $\alpha$-adaptin RNAi (BL32866), $\beta 2$-adaptin RNAi (BL28328), $\mu 2$-adaptin RNAi (BL28040). Other lines used in this study are: D42-Gal4 [63, 64], UAS-Tkv-EGFP (BL51653) [65], UAS-YFP-Rab11 S25N (BL9792) [66], UAS-Rab11Q70L_GFP (BL23260) [67], Rab11 ${ }^{\mathrm{EX} 2}$ and Rab1193Bi [52].

\section{Antibodies and Immunocytochemistry}

Wandering third instar larvae were dissected in cold calcium-free HL3 saline (70 mM NaCl, $5 \mathrm{mM}$ $\mathrm{KCl}, 20 \mathrm{mM} \mathrm{MgCl}$, $10 \mathrm{mM}$ NaHCO3, $5 \mathrm{mM}$ Trehalose, $115 \mathrm{mM}$ sucrose, and $5 \mathrm{mM}$ HEPES, $\mathrm{pH}$ 7.2) to expose the NMJs and fixed in $4 \%$ paraformaldehyde in phosphate-buffered saline (PBS, pH 7.2) for $30 \mathrm{~min}$ at room temperature. Fillets were then washed in PBS containing $0.15 \%$ Triton X100, blocked for 1 hour with 5\% bovine serum albumin (BSA) followed by overnight incubation with primary antibody at $4^{\circ} \mathrm{C}$. The monoclonal antibody anti-CSP $(1: 100)$ was obtained from the Developmental Studies Hybridoma Bank (DSHB). The polyclonal antibody against Rab5 [68] was a gift from Marino Zerial, Max Planck Institute, Germany. The polyclonal Rab7 and Rab11 [44, 69] antibodies were a gift from Tsubaka Tanaka, RIKEN Center for Developmental Biology, Japan. The secondary antibodies conjugated to Alexa Fluor 488 and Alexa Fluor 568 (Molecular Probes, Thermo Fisher Scientific) were used at 1:800 dilution. The Alexa Fluor 488 or Rhodamine conjugated anti-HRP (Jackson Immunoresearch, USA) were used at 1:800 dilution. Stained larval 
fillets were mounted in VECTASHIELD (Vector Laboratories, Burlingame, CA). All the images were captured with a laser scanning confocal microscope (LSM780, Carl Zeiss, Jena Germany or FV3000, Olympus Corporation, Japan).

\section{Electrophysiology}

All the intracellular recordings were performed on wandering third instar larvae as described previously [3]. Briefly, HL3 buffer containing $1.5 \mathrm{mM} \mathrm{Ca}^{2+}$ was used for the larval dissection. Recordings from muscle 6 of A2 hemisegment were performed using sharp glass electrodes having a resistance of 20-25 M $\Omega$ resistance. Miniature EJPs (mEJPs) were recorded for 60 seconds, followed by recordings of EJPs at $1 \mathrm{~Hz}$ stimulation. For High-frequency recording, nerves were stimulated at $10 \mathrm{~Hz}$, and EJPs were recorded for 5 minutes. For recording EJPs, stimulation pulse was delivered using Grass S88 stimulator (Grass Instruments, Astro-Med, Inc). The signals were amplified using Axoclamp 900A, digitized using Digidata 1440A, and acquired using pClamp10 software (Axon Instruments, Molecular device, USA). Muscles with resting membrane potential between $-60 \mathrm{mV}$ and $-75 \mathrm{mV}$ were used for analysis. The data were analyzed using the Mini Analysis program (Synaptosoft, Decatur, USA).

\section{Colocalization and Intensity profile}

Confocal images of muscle $4 \mathrm{NMJ}$ at A2 hemisegment were used to quantify the colocalization percentage between Rab5 and Tkv. From each NMJ, around ten random puncta were chosen and analyzed manually. To analyze the colocalization using motion tracker software, ROI was created around the NMJ. The intensity and size threshold were optimized for each NMJ so that the software randomly selects at least $10-15$ puncta in each NMJ for the colocalization analysis. To plot the intensity profile, a single bouton section was used, and the intensity of Tkv and HRP was analyzed throughout a line using Fiji/ ImageJ software. The graph was plotted in the excel file using the intensity values obtained from Fiji/ImageJ software. As the intensity of Tkv in control was too less to plot the graph, all the intensity values were multiplied by two. 


\section{Electron Microscopy}

TEM was performed as described previously [70]. Third instar larvae were dissected in cold PBS. The larval fillets were then fixed in $0.12 \mathrm{M}$ cacodylate buffer containing $2 \%$ glutaraldehyde for 10 minutes at room temperature, transferred to a fresh fixative, and kept overnight at $4^{\circ} \mathrm{C}$. The fillets were postfixed for 1 hour with $2 \%$ osmium tetroxide $(\mathrm{OsO} 4)$ solution prepared in $0.12 \mathrm{M}$ cacodylate buffer. The samples were rinsed with $0.12 \mathrm{M}$ cacodylate buffer followed by washes with distilled water to avoid precipitation of cacodylate with Uranyl acetate. Subsequently, the samples were subjected to en bloc staining with $2 \%$ uranyl acetate. The stained fillets were again washed with distilled water and dehydrated using graded solutions of ethanol before final infiltration of the samples through propylene oxide for 30 minutes. Stained and dehydrated fillets were embedded in epoxy resin and hardened overnight at $60^{\circ} \mathrm{C}$. Muscles embedded in epoxy resin were sectioned at $60 \mathrm{~nm}$. Ultrathin sections of the muscles stained with $2 \%$ uranyl acetate (in $70 \%$ ethanol) and 1\% aqueous lead citrate were examined at $120 \mathrm{KV}$ on a Tecnai G2 Spirit BioTWIN (FEI, USA) electron microscope. The number of synaptic vesicles per bouton were counted manually using the Multi-point tool in ImageJ/Fiji software and then divided by their respective bouton areas to obtain the vesicle density $/ \mu \mathrm{m}^{2}$ area of a bouton. For vesicle size, diameters of at least 100 vesicles from 10 bouton sections of each genotype were used for quantification.

\section{Quantification and statistical analysis}

For fluorescence quantification, images were captured using a laser scanning confocal microscope (LSM780; Carl Zeiss or FV3000, Olympus). All the control and experimental fillets were processed in the same way, and the fluorescence images were captured under the same settings for every experimental set. For bouton quantification, CSP labeled structures were counted at muscle 6/7 of A2 hemi-segment. The number of boutons from each NMJ was normalized to the respective muscle area. To calculate the bouton number, NMJs from A2 hemisegment were captured using a 40x objective, and all the CSP positive boutons were counted manually in ImageJ/Fiji software. For 
muscle area quantification, images from A2 hemisegment were captured using 20x objective, and the area was quantified using ZEN2 software (Carl Zeiss, Germany). For bouton number quantification, the total number of boutons per NMJ were divided by their respective muscle area. For fluorescence intensity quantification, NMJs from muscle 4 were captured using a $60 \mathrm{X}$ objective. For each NMJ, the fluorescence intensity from each bouton was subtracted from the background intensity, and the average intensity was normalized to the control. The fluorescence intensity was calculated using ImageJ/Fiji software. For bouton area quantification, NMJs from muscle 6/7 at A2 hemisegment were captured, and area was calculated by drawing a free-hand sketch around CSP positive bouton using ImageJ/Fiji software. The number of samples used for analysis is shown in the respective figure's histogram or mentioned in the legend. For multiple comparisons, one-way ANOVA followed by Post-hoc Tukey's test, and Student's t-test was used. GraphPad Prism 8 was used to plot the graph. Error bars in all the histograms represent the standard error of the mean (SEM). ${ }^{*} P<0.5, * * P<0.01, * * * P<0.001$.

\section{Acknowledgements}

We thank Dr. Tsubasa Tanaka for sharing Rab5, Rab7, and Rab11 antibodies and Dr. Marino Zerial for Rab5 antibodies. We thank Dr. Avital Rodal for sharing Rab11 mutants. We thank the Bloomington Drosophila Stock Center (BDSC), Vienna Drosophila RNAi Centre (VDRC), and Drosophila Genomics Resource Centre (DGRC) for fly stocks and Developmental Studies Hybridoma Bank (DSHB), the University of Iowa for monoclonal antibodies. We thank Manish Jaiswal and Jeet Kalia for helpful comments on the manuscript.

\section{Author Contribution}

S.D.C., M.K.D., and V.K. conceived and designed the experiments. M.K.D., S.D.C., A.P., and S.M. performed the experiments. M.K.D., S.D.C., and V.K. analyzed and wrote the manuscript with inputs from other authors. R.P provided resources and guidance for the TEM experiments. 
The authors declare no competing or financial interests. All the authors have read and approved the final version of the manuscript.

\section{Funding}

This work was partly supported by a project grant from the Science and Engineering Board (SERB Project No-EMR/2016/004718), the Government of India, and intramural funds from IISER Bhopal to V.K. 


\section{FIGURE LEGENDS}

Figure 1. Downregulating BMP signaling components rescue the synaptic overgrowth and clustering in the $\sigma 2$-adaptin mutant

(A-E') Confocal images of NMJ synapses at muscles 6/7 of A2 hemisegment showing the synaptic growth in $\left(\mathrm{A}, \quad \mathrm{A}^{\prime}\right) w^{1118}$ (Control), $\quad\left(\mathrm{B}, \quad \mathrm{B}^{\prime}\right) t k v^{7 /+}, \quad\left(\mathrm{C}, \quad \mathrm{C}^{\prime}\right) A P 2 \sigma^{K G 02457} / A P 2 \sigma^{\text {ang }}$,

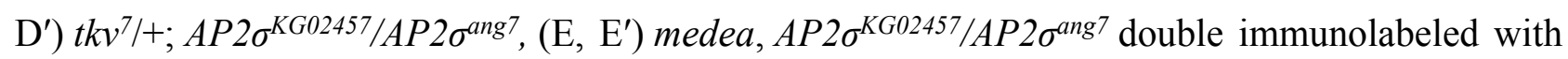
a pre-synaptic vesicle marker, CSP (magenta) and a neuronal membrane marker, HRP (green) to mark the bouton outline. Reducing the levels of BMP signaling components in the

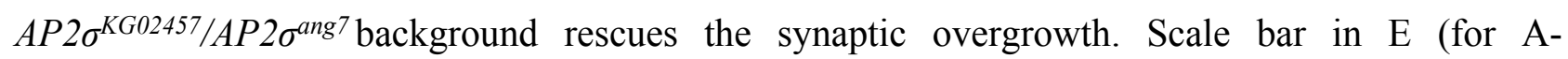
$\mathrm{E})$ and $\mathrm{E}^{\prime}$ (for $\mathrm{A}^{\prime}-\mathrm{E}^{\prime}$ ) represents 20 and $5 \mu \mathrm{m}$, respectively.

(F) Histogram showing the average bouton number normalized to the muscle area from muscle 6/7 $\mathrm{NMJ}$ at $\mathrm{A} 2$ hemisegment in control animals $(1.26 \pm 0.06), A P 2 \sigma^{K G 02457} /+(1.33 \pm 0.03), t k v^{7} /+(1.34$ $\pm 0.05), \quad A P 2 \sigma^{K G 02457} / A P 2 \sigma^{\text {ang }} \quad(2.85 \pm 0.08), \quad t k v^{7 /+} ; A P 2 \sigma^{K G 02457} / A P 2 \sigma^{\text {ang }} \quad(1.91 \pm 0.12)$ and medea, $A P 2 \sigma^{K G 02457 / A P 2 \sigma^{a n g 7}}(1.82 \pm 0.07)$. Error bar represents standard error of the mean (SEM); the statistical analysis was done using one-way ANOVA followed by post-hoc Tukey's test.

(G) Histogram showing the average bouton area from muscle 6/7 NMJ at A2 hemisegment in control animals $(9.57 \pm 0.53), \quad A P 2 \sigma^{K G 02457 /+}(8.89 \pm 0.35), \quad t k v^{7} /+(9.11 \pm 0.46)$, $A P 2 \sigma^{K G 02457} / A P 2 \sigma^{a n g 7} \quad(1.98 \quad \pm \quad 0.03), \quad t k v^{7} /+; A P 2 \sigma^{K G 02457} / A P 2 \sigma^{\text {ang } 7} \quad(2.85 \quad \pm \quad 0.05)$ and medea, $A P 2 \sigma^{K G 02457} / A P 2 \sigma^{a n g 7}(2.79 \pm 0.05)$. Error bar represents standard error of the mean (SEM); the statistical analysis was done using one-way ANOVA followed by post-hoc Tukey’s test. ${ }^{*} \mathrm{p}<0.05, * * \mathrm{p}<0.01, * * * \mathrm{p}<0.001$; ns, not significant.

Figure 2. $\sigma 2$-adaptin genetically interacts with $\mathrm{dad}$, the inhibitory Smad of BMP signaling 
(A-D) Confocal images of NMJ synapses at muscle 6/7 NMJ at A2 hemisegment showing the synaptic growth in (A) Control ( $\left.w^{1118}\right)$, (B) $A P 2 \sigma^{K G 02457 /+}$, (C) $\mathrm{dad}^{j 1 E 4 /+}$, and (D) $A P 2 \sigma^{K G 02457 /}$ $\operatorname{dad}^{j 1 E 4}$ double immunolabeled with a pre-synaptic synaptic vesicle marker, CSP (magenta) and a neuronal membrane marker, HRP (green) to mark the bouton outline. $\sigma 2$-adaptin and dad interact genetically, and trans-heterozygotes of $\sigma 2$-adaptin and dad mutants show significantly increased synaptic growth. Scale bar in (D) represents $20 \mu \mathrm{m}$.

(E) Histogram showing the average bouton number normalized to the muscle area from muscle 6/7 $\mathrm{NMJ}$ at A2 hemisegment in control animals $(1.26 \pm 0.06), A P 2 \sigma^{K G 02457 /+}(1.23 \pm 0.05)$, dad $^{j 1 E 4 /+}$ $(1.39 \pm 0.09)$ and $A P 2 \sigma^{K G 02457 / d a d^{i l E 4}}(1.89 \pm 0.09)$. Error bar represents standard error of the mean (SEM); the statistical analysis was done using one-way ANOVA followed by post-hoc Tukey's test. $* * * p<0.001$; ns, not significant.

Figure 3. Structural and functional deficits in $\sigma 2$-adaptin mutant can be genetically delineated (A) Representative traces of mEJP in control, heteroallelic $A P 2 \sigma^{K G 02457} / A P 2 \sigma^{a n g} 7$ and $t k v^{7 /+} ; A P 2 \sigma^{K G 02457 / A P 2 \sigma^{a n g 7} \text { larvae. }}$

(B) Representative traces of EJP in control, heteroallelic $A P 2 \sigma^{K G 02457} / A P 2 \sigma^{a n g 7}$ and

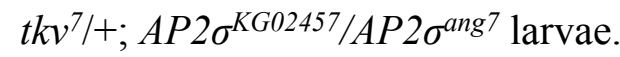

(C) Representative traces of EJPs under high-frequency stimulation of control,

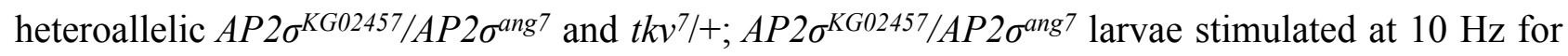
$5 \mathrm{~min}$ in $1.5 \mathrm{mM} \mathrm{Ca}^{2+}$ containing HL3.

(D) Quantification of quantal content in control (61.92 \pm 4.02$)$, heteroallelic $A P 2 \sigma^{K G 02457} / A P 2 \sigma^{a n g} 7$ $(39.29 \pm 5.81)$ and $t k v^{7} /+; A P 2 \sigma^{K G 02457} / A P 2 \sigma^{a n g 7}(38.2 \pm 3.09)$. At least $8 \mathrm{NMJ}$ recordings of each genotype were used for quantification. Error bars represent standard error of the mean (SEM); statistical analysis is based on one-way ANOVA followed by post-hoc Tukey's multiplecomparison test. ${ }^{* *} \mathrm{p}<0.01$; ns, not significant.

Figure 4. $\sigma 2$-adaptin mutant synapses show accumulation of large endosomal structures. 
(A-D) Electron micrographs of third instar type Ib boutons of control (A), $A P 2 \sigma^{K G 02457 / A P 2 \sigma^{a n g} 7}$ (B), and actin5C/+; AP2 $\sigma^{K G 02457}, U A S-A P 2 \sigma / A P 2 \sigma^{\text {ang7 }}(\mathrm{C})$. Arrows point to the large endosome-like structures observed in $A P 2 \sigma^{K G 02457} / A P 2 \sigma^{a n g 7}$ boutons but are absent in control and rescued boutons. The insets show the magnified area around the active zones. The pre-synaptic compartment is pseudocolored in cyan, and the sub-synaptic reticulum is marked in green. Scale bar represents $500 \mathrm{~nm}$.

(D) Histogram showing average vesicle diameter in control $(43.16 \pm 0.94), A P 2 \sigma^{K G 02457 / A P 2 \sigma^{a n g} 7}$ (71.53 \pm 3.7$)$, and $\operatorname{actin} 5 C /+; A P 2 \sigma^{K G 02457}, U A S-A P 2 \sigma / A P 2 \sigma^{a n g 7}(43.1 \pm 1.46)$.

(E) Histogram showing the SV density per unit area in control $(85.18 \pm 12.26)$, $A P 2 \sigma^{K G 02457} / A P 2 \sigma^{a n g 7}(28.02 \pm 14)$, and actin5C/+; AP2 $\sigma^{K G 02457}, U A S-A P 2 \sigma / A P 2 \sigma^{a n g 7}(107.9 \pm$ 11.32). At least 10 images from three different larvae per genotype were used for quantification. Error bar represents standard error of the mean (SEM); the statistical analysis was done using oneway ANOVA followed by post-hoc Tukey's test. ***p<0.001, **p $<0.01$.

\section{Figure 5. б2-adaptin mutant synapses show accumulation of Tkv-EGFP}

(A-D) Confocal images of NMJ synapses at muscle $4 \mathrm{NMJ}$ at A2 hemisegment in D42-Gal4/UAS$T k v-E G F P(\mathrm{~A}-\mathrm{B})$ and D42-Gal4, $A P 2 \sigma^{K G 02457} / A P 2 \sigma^{a n g 7}, U A S-T k v-E G F P$ (C-D). The neuronal membrane is marked with HRP (magenta), and EGFP fluorescence is shown in greyscale. The bouton area is outlined in the grey channel. Scale bar in (D) represents $5 \mu \mathrm{m}$.

(E) Histogram showing the relative Tkv level normalized to HRP in D42-Gal4/UAS-Tkv-EGFP $(100 \pm 9.36)$ and D42-Gal4, AP2 $\sigma^{K G 02457} / A P 2 \sigma^{a n g 7}, U A S-T k v-E G F P(135 \pm 7)$ synapses. Error bar represents standard error of the mean (SEM); the statistical analysis was done using Student's $t$ test. $* * p<0.01$

(F-K) A single confocal section of a bouton labeled for Tkv (represented in grayscale) and presynaptic membrane marker HRP (magenta) in D42-Gal4/UAS-Tkv-EGFP (F-G) or D42-

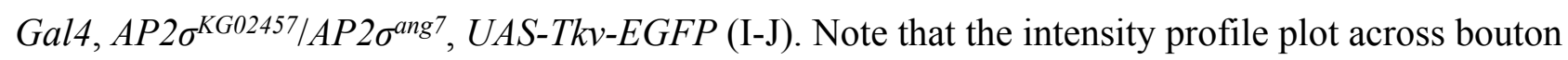


(shown in $\mathrm{G}$ and $\mathrm{J}$ as a thin line) shows that compared to control $(\mathrm{H})$, o2-adaptin mutant $(\mathrm{K})$ has more Tkv in at the membrane. Scale Bar in J represents $3 \mu \mathrm{m}$.

Figure 6. $\sigma 2$-adaptin mutant synapses show reduced colocalization of Tkv-EGFP punctae with the early endosomal marker, Rab5

(A-F) Confocal images of NMJ synapses at muscle 4 at A2 hemisegment in D42-Gal4/UAS-Tkv$\operatorname{EGFP}\left(\mathrm{A}-\mathrm{C}\right.$ ) and D42-Gal4, AP2 $\sigma^{K G 02457} / A P 2 \sigma^{a n g 7}, U A S-T k v-E G F P(\mathrm{D}-\mathrm{F})$ labelled for Tkv (green) and early endosomal marker, Rab5 (magenta). Arrows in panel $\mathrm{C}$ show colocalization between Tkv-EGFP and Rab5 in control NMJ synapses, whereas the two signals are distinct at the mutant synapses (panel F). Scale bar in F represents $5 \mu \mathrm{m}$.

(G) Histogram showing the percentage of Rab5 punctae positive for Tkv-EGFP in D42-Gal4/UAS$T k v-E G F P(65.74 \pm 3.75)$ and D42-Gal4, AP2 $\sigma^{K G 02457} / A P 2 \sigma^{a n g 7}, U A S-T k v-E G F P(27.4 \pm 3.82)$ synapses. Error bar represents standard error of the mean (SEM); the statistical analysis was done using Student's $t$-test. ${ }^{* *} p<0.001$.

(H-M) Confocal images of boutons from muscle 4 at A2 hemisegment in control and $A P 2 \sigma^{K G 02457} / A P 2 \sigma^{a n g 7}$, immunolabelled for Rab5 (magenta) and HRP (green). Scale bar in M represents $5 \mu \mathrm{m}$.

(N) Histogram showing the Rab5 level in control $(100.0 \pm 3.0)$ and $A P 2 \sigma^{K G 02457} / A P 2 \sigma^{a n g 7}(97.25 \pm$ 4.81) synapse. Error bar represents standard error of the mean (SEM); the statistical analysis was done using Student's $t$-test. ns, not significant.

Figure 7. 2-adaptin mutant synapses show a reduction in the recycling endosome marker,

\section{Rab11}

(A-H) Confocal images of NMJ synapses at muscle 4 of A2 hemisegment in control (A-B), $A P 2 \sigma^{K G 02457} / A P 2 \sigma^{a n g 7}(\mathrm{C}-\mathrm{D}), D 42-G a l 4, A P 2 \sigma^{K G 02457} / U A S-A P 2 \sigma, A P 2 \sigma^{a n g 7}(\mathrm{E}-\mathrm{F})$ and $R a b 11^{E X 2 / 93 B i}$ (G-H) double immunolabeled with recycling endosomal marker, Rab11 (represented in 
grayscale/green) and neuronal membrane marker, HRP (magenta). Scale bar in $(\mathrm{H})$ represents $3 \mu \mathrm{m}$.

(I) Histogram showing the relative Tkv level normalized to HRP in control $(100 \pm 5.73)$, $A P 2 \sigma^{K G 02457 / A P 2 \sigma^{a n g 7}}(61.81 \pm 7.11) ; D 42-G a l 4, A P 2 \sigma^{K G 02457 / U A S-A P 2 \sigma, A P 2 \sigma^{a n g 7}}(112.9 \pm 8.29)$ and $R a b 11^{E X 2 / 93 B i}(14.21 \pm 1.57)$ synapses. Error bar represents standard error of the mean (SEM); the statistical analysis was done using Student's $t$-test. ${ }^{* * *} p<0.001$; ns, not significant.

Figure 8. Rab11 mutants phenocopy $\sigma 2$-adaptin mutations and show elevated levels of synaptic pMAD and Tkv receptors.

(A-D) Confocal images of NMJ synapses at muscle 6/7 NMJ at A2 hemisegment in control (A), Rab11 ex2/93Bi (B), D42-Gal4 driven dominant negative YFP-Rab11 ${ }^{S 25 N}$ (C) and $A P 2 \sigma^{K G 02457} / A P 2 \sigma^{a n g 7}(\mathrm{D})$ double immunolabeled with a pre-synaptic synaptic vesicle marker, CSP (magenta) and a neuronal membrane marker, HRP (green) to mark the bouton outline. Scale bar in D represents $20 \mu \mathrm{m}$.

(E-L) Confocal images of NMJ from muscle 4 at A2 hemisegment in control (E-F), Rab1 1 ex2/93Bi (G-H), D42-Gal4 driven dominant-negative $Y F P-R a b 11^{S 25 N}(\mathrm{I}-\mathrm{J})$ and $A P 2 \sigma^{K G 02457} / A P 2 \sigma^{a n g 7}(\mathrm{~K}-\mathrm{L})$ double immunolabeled with pMAD (green) and a neuronal membrane marker, HRP (magenta) to mark the bouton outline. Scale bar in L represents $5 \mu \mathrm{m}$.

(M-P) Confocal images of NMJ from muscle 4 at A2 hemisegment in control D42-Gal4 driven Tkv-EGFP (M-N) and D42-Gal4 driven Tkv-EGFP, Rab1 1 ex2/93Bi (O-P). Scale bar in P represents $5 \mu \mathrm{m}$.

(Q) Histogram showing the average bouton number normalized to the muscle area from muscle 6/7 $\mathrm{NMJ}$ at A2 hemisegment in control $w^{1118}(1.56 \pm 0.06)$, Rab1 1 ${ }^{\text {ex2/93Bi }}(2.77 \pm 0.11)$, D42-Gal4 driven dominant-negative $Y F P-R a b 11^{S 25 N}(2.26 \pm 0.08)$ and $\mathrm{AP} 2 \sigma^{K G 02457 / A P 2 \sigma^{a n g 7}}(2.83 \pm 0.12)$. Error bar represents standard error of the mean (SEM); the statistical analysis was done using oneway ANOVA followed by post-hoc Tukey's test. $* * * p<0.001$. 
(R) Histogram showing the levels of pMAD normalized with HRP from muscle 4 at A2 hemisegment in control $(100 \pm 5.87), R^{2} a b 11^{\text {ex2/93Bi }}(147.9 \pm 8.58)$, D42 driven YFP-Rab1 $1^{S 25 N}$ $(134.2 \pm 4.36)$, and $A P 2 \sigma^{K G 02457 / A P 2 \sigma^{a n g 7}}(218.8 \pm 7.5)$. Error bar represents standard error of the mean (SEM); the statistical analysis was done using one-way ANOVA followed by post-hoc Tukey's test. $* * * p<0.001, * * \mathrm{p}<0.01,{ }^{*} \mathrm{p}<0.05$

(S) Histogram showing the relative Tkv level normalized to HRP in D42-Gal4 driven Tkv-EGFP $(100 \pm 8.71)$, and D42-Gal4, Rab1 1 $1^{e x 2} /$ Tkv-EGFP, Rab11 $1^{93 B i}(189.5 \pm 10.57)$. Error bar represents standard error of the mean (SEM); the statistical analysis was done using Student's $t$-test. $* * * p<0.001$

\section{Figure 9. Model depicting the role of $\sigma 2$-adaptin in BMP receptor trafficking at the NMJ.}

The model depicts a novel function of $\sigma 2$-adaptin in BMP receptor trafficking at the Drosophila NMJ. Retrograde NMJ growth signaling in Drosophila involves Gbb ligand that is secreted from postsynaptic muscles and binds to BMP receptors on the presynaptic membrane to activate them [7, 12]. Activated receptors are then internalized through $\mathrm{CME}$ and fuse with early endosomes to trigger the downstream signaling cascade [71]. From early endosomes, receptors either get sorted to the Rab11-positive recycling endosomes that recycle them back to the presynaptic membrane or are sorted for lysosomal degradation [9, 28]. Depleting 62 -adaptin/AP2-complex perturbs endocytosis and Rab11-mediated recycling of type-I BMP receptor, Thickveins (Tkv) leading to its accumulation at the presynaptic membrane and early endosomes. Enrichment of Tkv receptors at the presynaptic membrane in the early endosome leads to elevated BMP signaling resulting in synaptic overgrowth. 


\section{REFERENCES}

1. Ball RW, Warren-Paquin M, Tsurudome K, Liao EH, Elazzouzi F, Cavanagh C, et al. Retrograde BMP signaling controls synaptic growth at the NMJ by regulating trio expression in motor neurons. Neuron. 2010;66(4):536-49. Epub 2010/06/01. doi: 10.1016/j.neuron.2010.04.011. PubMed PMID: 20510858.

2. Budnik V, Salinas PC. Wnt signaling during synaptic development and plasticity. Curr Opin Neurobiol. 2011;21(1):151-9. Epub 2011/01/18. doi: 10.1016/j.conb.2010.12.002. PubMed PMID: 21239163; PubMed Central PMCID: PMCPMC3499977.

3. Choudhury SD, Mushtaq Z, Reddy-Alla S, Balakrishnan SS, Thakur RS, Krishnan KS, et al. sigma2-Adaptin Facilitates Basal Synaptic Transmission and Is Required for Regenerating Endo-Exo Cycling Pool Under High-Frequency Nerve Stimulation in Drosophila. Genetics. 2016;203(1):369-85. Epub 2016/02/28. doi: 10.1534/genetics.115.183863. PubMed PMID: 26920756; PubMed Central PMCID: PMCPMC4858786.

4. Collins CA, Wairkar YP, Johnson SL, DiAntonio A. Highwire restrains synaptic growth by attenuating a MAP kinase signal. Neuron. 2006;51(1):57-69. Epub 2006/07/04. doi: 10.1016/j.neuron.2006.05.026. PubMed PMID: 16815332.

5. Franco B, Bogdanik L, Bobinnec Y, Debec A, Bockaert J, Parmentier ML, et al. Shaggy, the homolog of glycogen synthase kinase 3 , controls neuromuscular junction growth in Drosophila. J Neurosci. 2004;24(29):6573-7. Epub 2004/07/23. doi: 10.1523/JNEUROSCI.1580-04.2004. PubMed PMID: 15269269; PubMed Central PMCID: PMCPMC6729875.

6. McCabe BD, Hom S, Aberle H, Fetter RD, Marques G, Haerry TE, et al. Highwire regulates presynaptic BMP signaling essential for synaptic growth. Neuron. 2004;41(6):891-905. Epub 2004/03/30. doi: 10.1016/s0896-6273(04)00073-x. PubMed PMID: 15046722.

7. McCabe BD, Marques G, Haghighi AP, Fetter RD, Crotty ML, Haerry TE, et al. The BMP homolog Gbb provides a retrograde signal that regulates synaptic growth at the Drosophila neuromuscular junction. Neuron. 2003;39(2):241-54. Epub 2003/07/23. doi: 10.1016/s08966273(03)00426-4. PubMed PMID: 12873382.

8. Piccioli ZD, Littleton JT. Retrograde BMP signaling modulates rapid activity-dependent synaptic growth via presynaptic LIM kinase regulation of cofilin. J Neurosci. 2014;34(12):4371-81. Epub 2014/03/22. doi: 10.1523/JNEUROSCI.4943-13.2014. PubMed PMID: 24647957; PubMed Central PMCID: PMCPMC3960475.

9. Deshpande M, Rodal AA. The Crossroads of Synaptic Growth Signaling, Membrane Traffic and Neurological Disease: Insights from Drosophila. Traffic. 2016;17(2):87-101. Epub 2015/11/06. doi: 10.1111/tra.12345. PubMed PMID: 26538429.

10. Marques G, Bao H, Haerry TE, Shimell MJ, Duchek P, Zhang B, et al. The Drosophila BMP type II receptor Wishful Thinking regulates neuromuscular synapse morphology and function. Neuron. 2002;33(4):529-43. Epub 2002/02/22. doi: 10.1016/s0896-6273(02)00595-0. PubMed PMID: 11856528.

11. O'Connor-Giles KM, Ho LL, Ganetzky B. Nervous wreck interacts with thickveins and the endocytic machinery to attenuate retrograde BMP signaling during synaptic growth. Neuron. 2008;58(4):507-18. Epub 2008/05/24. doi: 10.1016/j.neuron.2008.03.007. PubMed PMID: 18498733; PubMed Central PMCID: PMCPMC2448395. 
12. Aberle H, Haghighi AP, Fetter RD, McCabe BD, Magalhaes TR, Goodman CS. wishful thinking encodes a BMP type II receptor that regulates synaptic growth in Drosophila. Neuron.

2002;33(4):545-58. Epub 2002/02/22. doi: 10.1016/s0896-6273(02)00589-5. PubMed PMID: 11856529.

13. Vuilleumier R, Lian T, Flibotte $S$, Khan ZN, Fuchs A, Pyrowolakis G, et al. Retrograde BMP signaling activates neuronal gene expression through widespread deployment of a conserved BMPresponsive cis-regulatory activation element. Nucleic Acids Res. 2019;47(2):679-99. Epub 2018/11/27. doi: 10.1093/nar/gky1135. PubMed PMID: 30476189; PubMed Central PMCID: PMCPMC6344883.

14. Upadhyay A, Moss-Taylor L, Kim MJ, Ghosh AC, O'Connor MB. TGF-beta Family Signaling in Drosophila. Cold Spring Harb Perspect Biol. 2017;9(9). Epub 2017/01/29. doi:

10.1101/cshperspect.a022152. PubMed PMID: 28130362; PubMed Central PMCID: PMCPMC5585851.

15. Nahm M, Long AA, Paik SK, Kim S, Bae YC, Broadie K, et al. The Cdc42-selective GAP rich regulates postsynaptic development and retrograde BMP transsynaptic signaling. J Cell Biol. 2010;191(3):661-75. Epub 2010/11/03. doi: 10.1083/jcb.201007086. PubMed PMID: 21041451; PubMed Central PMCID: PMCPMC3003324.

16. Shi W, Chen Y, Gan G, Wang D, Ren J, Wang Q, et al. Brain tumor regulates neuromuscular synapse growth and endocytosis in Drosophila by suppressing mad expression. J Neurosci. 2013;33(30):12352-63. Epub 2013/07/26. doi: 10.1523/JNEUROSCI.0386-13.2013. PubMed PMID: 23884941; PubMed Central PMCID: PMCPMC6618673.

17. Rodal AA, Blunk AD, Akbergenova Y, Jorquera RA, Buhl LK, Littleton JT. A presynaptic endosomal trafficking pathway controls synaptic growth signaling. J Cell Biol. 2011;193(1):201-17. Epub 2011/04/06. doi: 10.1083/jcb.201009052. PubMed PMID: 21464232; PubMed Central PMCID: PMCPMC3082179.

18. Cosker KE, Segal RA. Neuronal signaling through endocytosis. Cold Spring Harb Perspect Biol. 2014;6(2). Epub 2014/02/05. doi: 10.1101/cshperspect.a020669. PubMed PMID: 24492712; PubMed Central PMCID: PMCPMC3941234.

19. Koh TW, Verstreken P, Bellen HJ. Dap160/intersectin acts as a stabilizing scaffold required for synaptic development and vesicle endocytosis. Neuron. 2004;43(2):193-205. Epub 2004/07/21. doi: 10.1016/j.neuron.2004.06.029. PubMed PMID: 15260956.

20. Dickman DK, Lu Z, Meinertzhagen IA, Schwarz TL. Altered synaptic development and active zone spacing in endocytosis mutants. Curr Biol. 2006;16(6):591-8. Epub 2006/03/21. doi: 10.1016/j.cub.2006.02.058. PubMed PMID: 16546084.

21. Di Fiore PP, De Camilli P. Endocytosis and signaling. an inseparable partnership. Cell. 2001;106(1):1-4. Epub 2001/07/20. doi: 10.1016/s0092-8674(01)00428-7. PubMed PMID: 11461694. 22. Dubois L, Lecourtois M, Alexandre C, Hirst E, Vincent JP. Regulated endocytic routing modulates wingless signaling in Drosophila embryos. Cell. 2001;105(5):613-24. Epub 2001/06/08. doi: 10.1016/s0092-8674(01)00375-0. PubMed PMID: 11389831.

23. Sweeney ST, Davis GW. Unrestricted synaptic growth in spinster-a late endosomal protein implicated in TGF-beta-mediated synaptic growth regulation. Neuron. 2002;36(3):403-16. Epub 2002/11/01. doi: 10.1016/s0896-6273(02)01014-0. PubMed PMID: 12408844.

24. Kelly EE, Horgan CP, Goud B, McCaffrey MW. The Rab family of proteins: 25 years on. Biochem Soc Trans. 2012;40(6):1337-47. Epub 2012/11/28. doi: 10.1042/BST20120203. PubMed PMID: 23176478.

25. Horgan CP, McCaffrey MW. Rab GTPases and microtubule motors. Biochem Soc Trans. 2011;39(5):1202-6. Epub 2011/09/23. doi: 10.1042/BST0391202. PubMed PMID: 21936789.

26. Chavrier P, Parton RG, Hauri HP, Simons K, Zerial M. Localization of low molecular weight GTP binding proteins to exocytic and endocytic compartments. Cell. 1990;62(2):317-29. Epub 1990/07/27. doi: 10.1016/0092-8674(90)90369-p. PubMed PMID: 2115402. 
27. Ullrich $\mathrm{O}$, Reinsch S, Urbe $\mathrm{S}$, Zerial M, Parton RG. Rab11 regulates recycling through the pericentriolar recycling endosome. J Cell Biol. 1996;135(4):913-24. Epub 1996/11/01. doi: 10.1083/jcb.135.4.913. PubMed PMID: 8922376; PubMed Central PMCID: PMCPMC2133374. 28. Liu Z, Huang Y, Hu W, Huang S, Wang Q, Han J, et al. dAcsl, the Drosophila ortholog of acylCoA synthetase long-chain family member 3 and 4 , inhibits synapse growth by attenuating bone morphogenetic protein signaling via endocytic recycling. J Neurosci. 2014;34(8):2785-96. Epub 2014/02/21. doi: 10.1523/JNEUROSCI.3547-13.2014. PubMed PMID: 24553921; PubMed Central PMCID: PMCPMC6608520.

29. Rodal AA, Motola-Barnes RN, Littleton JT. Nervous wreck and Cdc42 cooperate to regulate endocytic actin assembly during synaptic growth. J Neurosci. 2008;28(33):8316-25. Epub 2008/08/15. doi: 10.1523/JNEUROSCI.2304-08.2008. PubMed PMID: 18701694; PubMed Central PMCID: PMCPMC2546611.

30. Kononenko NL, Puchkov D, Classen GA, Walter AM, Pechstein A, Sawade L, et al. Clathrin/AP2 mediate synaptic vesicle reformation from endosome-like vacuoles but are not essential for membrane retrieval at central synapses. Neuron. 2014;82(5):981-8. Epub 2014/06/09. doi: 10.1016/j.neuron.2014.05.007. PubMed PMID: 24908483.

31. Watanabe S, Trimbuch T, Camacho-Perez M, Rost BR, Brokowski B, Sohl-Kielczynski B, et al. Clathrin regenerates synaptic vesicles from endosomes. Nature. 2014;515(7526):228-33. Epub 2014/10/09. doi: 10.1038/nature13846. PubMed PMID: 25296249; PubMed Central PMCID: PMCPMC4291189.

32. Lloyd TE, Atkinson R, Wu MN, Zhou Y, Pennetta G, Bellen HJ. Hrs regulates endosome membrane invagination and tyrosine kinase receptor signaling in Drosophila. Cell. 2002;108(2):2619. Epub 2002/02/08. doi: 10.1016/s0092-8674(02)00611-6. PubMed PMID: 11832215. 33. Wang X, Shaw WR, Tsang HT, Reid E, O'Kane CJ. Drosophila spichthyin inhibits BMP signaling and regulates synaptic growth and axonal microtubules. Nat Neurosci. 2007;10(2):177-85. Epub 2007/01/16. doi: 10.1038/nn1841. PubMed PMID: 17220882; PubMed Central PMCID: PMCPMC2464677.

34. Joseph BB, Wang Y, Edeen P, Lazetic V, Grant BD, Fay DS. Control of clathrin-mediated endocytosis by NIMA family kinases. PLoS Genet. 2020;16(2):e1008633. Epub 2020/02/19. doi: 10.1371/journal.pgen.1008633. PubMed PMID: 32069276; PubMed Central PMCID: PMCPMC7048319.

35. Papagiannouli F, Berry CW, Fuller MT. The Dlg Module and Clathrin-Mediated Endocytosis Regulate EGFR Signaling and Cyst Cell-Germline Coordination in the Drosophila Testis. Stem Cell Reports. 2019;12(5):1024-40. Epub 2019/04/23. doi: 10.1016/j.stemcr.2019.03.008. PubMed PMID: 31006632; PubMed Central PMCID: PMCPMC6523063.

36. Kim N, Kim S, Nahm M, Kopke D, Kim J, Cho E, et al. BMP-dependent synaptic development requires Abi-Abl-Rac signaling of BMP receptor macropinocytosis. Nat Commun. 2019;10(1):684. Epub 2019/02/10. doi: 10.1038/s41467-019-08533-2. PubMed PMID: 30737382; PubMed Central PMCID: PMCPMC6368546.

37. Zhao L, Wang D, Wang Q, Rodal AA, Zhang YQ. Drosophila cyfip regulates synaptic development and endocytosis by suppressing filamentous actin assembly. PLoS Genet. 2013;9(4):e1003450. Epub 2013/04/18. doi: 10.1371/journal.pgen.1003450. PubMed PMID: 23593037; PubMed Central PMCID: PMCPMC3616907.

38. Hata A, Lagna G, Massague J, Hemmati-Brivanlou A. Smad6 inhibits BMP/Smad1 signaling by specifically competing with the Smad4 tumor suppressor. Genes Dev. 1998;12(2):186-97. Epub 1998/03/07. doi: 10.1101/gad.12.2.186. PubMed PMID: 9436979; PubMed Central PMCID: PMCPMC316444.

39. Mitchell H, Choudhury A, Pagano RE, Leof EB. Ligand-dependent and -independent transforming growth factor-beta receptor recycling regulated by clathrin-mediated endocytosis and Rab11. Mol Biol Cell. 2004;15(9):4166-78. Epub 2004/07/02. doi: 10.1091/mbc.e04-03-0245.

PubMed PMID: 15229286; PubMed Central PMCID: PMCPMC515349. 
40. Kawasaki F, lyer J, Posey LL, Sun CE, Mammen SE, Yan H, et al. The DISABLED protein functions in CLATHRIN-mediated synaptic vesicle endocytosis and exoendocytic coupling at the active zone. Proc Natl Acad Sci U S A. 2011;108(25):E222-9. Epub 2011/05/25. doi: 10.1073/pnas.1102231108. PubMed PMID: 21606364; PubMed Central PMCID: PMCPMC3121831. 41. Kasprowicz J, Kuenen S, Miskiewicz K, Habets RL, Smitz L, Verstreken P. Inactivation of clathrin heavy chain inhibits synaptic recycling but allows bulk membrane uptake. J Cell Biol. 2008;182(5):1007-16. Epub 2008/09/03. doi: 10.1083/jcb.200804162. PubMed PMID: 18762582; PubMed Central PMCID: PMCPMC2528586.

42. Zhang B, Koh YH, Beckstead RB, Budnik V, Ganetzky B, Bellen HJ. Synaptic vesicle size and number are regulated by a clathrin adaptor protein required for endocytosis. Neuron.

1998;21(6):1465-75. Epub 1999/01/12. doi: 10.1016/s0896-6273(00)80664-9. PubMed PMID: 9883738.

43. Shimizu H, Kawamura S, Ozaki K. An essential role of Rab5 in uniformity of synaptic vesicle size. J Cell Sci. 2003;116(Pt 17):3583-90. Epub 2003/07/24. doi: 10.1242/jcs.00676. PubMed PMID: 12876219.

44. West RJ, Lu Y, Marie B, Gao FB, Sweeney ST. Rab8, POSH, and TAK1 regulate synaptic growth in a Drosophila model of frontotemporal dementia. J Cell Biol. 2015;208(7):931-47. Epub 2015/03/25. doi: 10.1083/jcb.201404066. PubMed PMID: 25800055; PubMed Central PMCID: PMCPMC4384727.

45. Inoshita T, Arano T, Hosaka Y, Meng H, Umezaki Y, Kosugi S, et al. Vps35 in cooperation with LRRK2 regulates synaptic vesicle endocytosis through the endosomal pathway in Drosophila. Hum Mol Genet. 2017;26(15):2933-48. Epub 2017/05/10. doi: 10.1093/hmg/ddx179. PubMed PMID: 28482024.

46. Kadlecova Z, Spielman SJ, Loerke D, Mohanakrishnan A, Reed DK, Schmid SL. Regulation of clathrin-mediated endocytosis by hierarchical allosteric activation of AP2. J Cell Biol.

2017;216(1):167-79. Epub 2016/12/23. doi: 10.1083/jcb.201608071. PubMed PMID: 28003333; PubMed Central PMCID: PMCPMC5223608.

47. Jovic M, Sharma M, Rahajeng J, Caplan S. The early endosome: a busy sorting station for proteins at the crossroads. Histol Histopathol. 2010;25(1):99-112. Epub 2009/11/20. doi: 10.14670/HH-25.99. PubMed PMID: 19924646; PubMed Central PMCID: PMCPMC2810677. 48. Gruenberg J, Griffiths G, Howell KE. Characterization of the early endosome and putative endocytic carrier vesicles in vivo and with an assay of vesicle fusion in vitro. J Cell Biol. 1989;108(4):1301-16. Epub 1989/04/01. doi: 10.1083/jcb.108.4.1301. PubMed PMID: 2538480; PubMed Central PMCID: PMCPMC2115527.

49. Dunn KW, McGraw TE, Maxfield FR. Iterative fractionation of recycling receptors from lysosomally destined ligands in an early sorting endosome. J Cell Biol. 1989;109(6 Pt 2):3303-14. Epub 1989/12/01. doi: 10.1083/jcb.109.6.3303. PubMed PMID: 2600137; PubMed Central PMCID: PMCPMC2115921.

50. Collinet C, Stoter M, Bradshaw CR, Samusik N, Rink JC, Kenski D, et al. Systems survey of endocytosis by multiparametric image analysis. Nature. 2010;464(7286):243-9. Epub 2010/03/02. doi: 10.1038/nature08779. PubMed PMID: 20190736.

51. Rink J, Ghigo E, Kalaidzidis Y, Zerial M. Rab conversion as a mechanism of progression from early to late endosomes. Cell. 2005;122(5):735-49. Epub 2005/09/07. doi:

10.1016/j.cell.2005.06.043. PubMed PMID: 16143105.

52. Khodosh R, Augsburger A, Schwarz TL, Garrity PA. Bchs, a BEACH domain protein, antagonizes Rab11 in synapse morphogenesis and other developmental events. Development. 2006;133(23):4655-65. Epub 2006/11/03. doi: 10.1242/dev.02650. PubMed PMID: 17079274. 53. Deshpande M, Feiger Z, Shilton AK, Luo CC, Silverman E, Rodal AA. Role of BMP receptor traffic in synaptic growth defects in an ALS model. Mol Biol Cell. 2016;27(19):2898-910. Epub 2016/08/19. doi: 10.1091/mbc.E16-07-0519. PubMed PMID: 27535427; PubMed Central PMCID: PMCPMC5042577. 
54. Verstreken P, Kjaerulff O, Lloyd TE, Atkinson R, Zhou Y, Meinertzhagen IA, et al. Endophilin mutations block clathrin-mediated endocytosis but not neurotransmitter release. Cell. 2002;109(1):101-12. Epub 2002/04/17. doi: 10.1016/s0092-8674(02)00688-8. PubMed PMID: 11955450.

55. Verstreken P, Koh TW, Schulze KL, Zhai RG, Hiesinger PR, Zhou Y, et al. Synaptojanin is recruited by endophilin to promote synaptic vesicle uncoating. Neuron. 2003;40(4):733-48. Epub 2003/11/19. doi: 10.1016/s0896-6273(03)00644-5. PubMed PMID: 14622578.

56. Rikhy R, Kumar V, Mittal R, Krishnan KS. Endophilin is critically required for synapse formation and function in Drosophila melanogaster. J Neurosci. 2002;22(17):7478-84. Epub 2002/08/28. PubMed PMID: 12196570; PubMed Central PMCID: PMCPMC6758002.

57. Packard M, Koo ES, Gorczyca M, Sharpe J, Cumberledge S, Budnik V. The Drosophila Wnt, wingless, provides an essential signal for pre- and postsynaptic differentiation. Cell. 2002;111(3):319-30. Epub 2002/11/07. doi: 10.1016/s0092-8674(02)01047-4. PubMed PMID: 12419243; PubMed Central PMCID: PMCPMC3499980.

58. Brunner P, Hastar N, Kaehler C, Burdzinski W, Jatzlau J, Knaus P. AMOT130 drives BMPSMAD signaling at the apical membrane in polarized cells. Mol Biol Cell. 2020;31(2):118-30. Epub 2019/12/05. doi: 10.1091/mbc.E19-03-0179. PubMed PMID: 31800378; PubMed Central PMCID: PMCPMC6960409.

59. Smith RB, Machamer JB, Kim NC, Hays TS, Marques G. Relay of retrograde synaptogenic signals through axonal transport of BMP receptors. J Cell Sci. 2012;125(Pt 16):3752-64. Epub 2012/05/11. doi: 10.1242/jcs.094292. PubMed PMID: 22573823; PubMed Central PMCID: PMCPMC3462079.

60. Tao B, Kraehling JR, Ghaffari S, Ramirez CM, Lee S, Fowler JW, et al. BMP-9 and LDL crosstalk regulates ALK-1 endocytosis and LDL transcytosis in endothelial cells. J Biol Chem.

2020;295(52):18179-88. Epub 2020/10/25. doi: 10.1074/jbc.RA120.015680. PubMed PMID: 33097593.

61. Gui J, Huang Y, Shimmi O. Scribbled Optimizes BMP Signaling through Its Receptor Internalization to the Rab5 Endosome and Promote Robust Epithelial Morphogenesis. PLoS Genet. 2016;12(11):e1006424. Epub 2016/11/05. doi: 10.1371/journal.pgen.1006424. PubMed PMID: 27814354; PubMed Central PMCID: PMCPMC5096713.

62. Tracy Cai X, Li H, Safyan A, Gawlik J, Pyrowolakis G, Jasper H. AWD regulates timed activation of BMP signaling in intestinal stem cells to maintain tissue homeostasis. Nat Commun.

2019;10(1):2988. Epub 2019/07/07. doi: 10.1038/s41467-019-10926-2. PubMed PMID: 31278345; PubMed Central PMCID: PMCPMC6611797.

63. Sanyal S. Genomic mapping and expression patterns of C380, OK6 and D42 enhancer trap lines in the larval nervous system of Drosophila. Gene Expr Patterns. 2009;9(5):371-80. Epub 2009/07/16. doi: 10.1016/j.gep.2009.01.002. PubMed PMID: 19602393.

64. Yeh E, Gustafson K, Boulianne GL. Green fluorescent protein as a vital marker and reporter of gene expression in Drosophila. Proc Natl Acad Sci U S A. 1995;92(15):7036-40. Epub 1995/07/18. doi: 10.1073/pnas.92.15.7036. PubMed PMID: 7624365; PubMed Central PMCID: PMCPMC41466. 65. Ayyaz A, Li H, Jasper H. Haemocytes control stem cell activity in the Drosophila intestine. Nat Cell Biol. 2015;17(6):736-48. Epub 2015/05/26. doi: 10.1038/ncb3174. PubMed PMID: 26005834; PubMed Central PMCID: PMCPMC4449816.

66. Guan Z, Quinones-Frias MC, Akbergenova Y, Littleton JT. Drosophila Synaptotagmin 7 negatively regulates synaptic vesicle release and replenishment in a dosage-dependent manner. Elife. 2020;9. Epub 2020/04/29. doi: 10.7554/eLife.55443. PubMed PMID: 32343229; PubMed Central PMCID: PMCPMC7224696.

67. Sorvina A, Shandala T, Brooks DA. Drosophila Pkaap regulates Rab4/Rab11-dependent traffic and Rab11 exocytosis of innate immune cargo. Biol Open. 2016;5(6):678-88. Epub 2016/05/18. doi: 10.1242/bio.016642. PubMed PMID: 27190105; PubMed Central PMCID: PMCPMC4920182. 
bioRxiv preprint doi: https://doi. org/10.1101/2021.01 28.428584 this version posted January 28, 2021. The copyright holder for this preprint (which was not certified by peer review) is the author/funder. This article is a US Government work. It is not subject to copyright under 17 USC 105 and is also made available for use under a CCO license.

68. Mottola G, Classen AK, Gonzalez-Gaitan M, Eaton S, Zerial M. A novel function for the Rab5 effector Rabenosyn-5 in planar cell polarity. Development. 2010;137(14):2353-64. Epub 2010/06/11. doi: 10.1242/dev.048413. PubMed PMID: 20534670.

69. Tanaka T, Nakamura A. The endocytic pathway acts downstream of Oskar in Drosophila germ plasm assembly. Development. 2008;135(6):1107-17. Epub 2008/02/15. doi:

10.1242/dev.017293. PubMed PMID: 18272590.

70. Deivasigamani S, Basargekar A, Shweta K, Sonavane P, Ratnaparkhi GS, Ratnaparkhi A. A Presynaptic Regulatory System Acts Transsynaptically via Mon1 to Regulate Glutamate Receptor Levels in Drosophila. Genetics. 2015;201(2):651-64. Epub 2015/08/21. doi:

10.1534/genetics.115.177402. PubMed PMID: 26290519; PubMed Central PMCID: PMCPMC4596675.

71. Hartung A, Bitton-Worms K, Rechtman MM, Wenzel V, Boergermann JH, Hassel S, et al. Different routes of bone morphogenic protein (BMP) receptor endocytosis influence BMP signaling. Mol Cell Biol. 2006;26(20):7791-805. Epub 2006/08/23. doi: 10.1128/MCB.00022-06. PubMed PMID: 16923969; PubMed Central PMCID: PMCPMC1636853. 
A

\section{Control}

bioRxiv preprint doi: https://doi.org/10.1101/2021 01 28.428584 this version posted January 28, 2021. The copyright holder for this preprint (which was not certified by peer review) is the author/funder. This article is a US Government work. It is not sublect to copyrigh
B

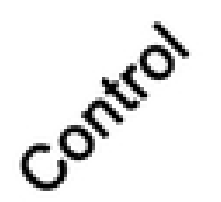

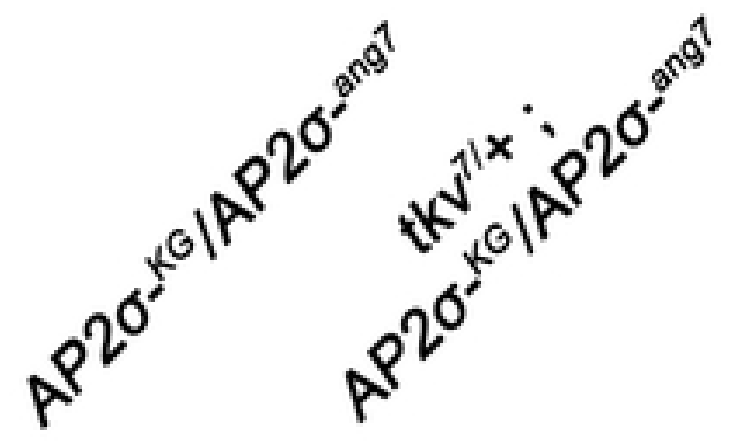

\section{$A P 2 \sigma-{ }^{K G} / A P 2 \sigma-{ }_{-a n g}$}

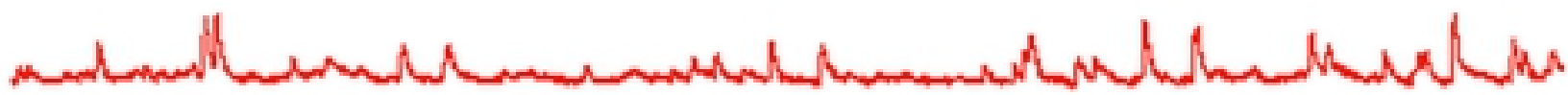

$$
t k v^{7 /+} ; A P 2 \sigma_{-}{ }^{K G} / A P 2 \sigma-^{\text {ang }}
$$

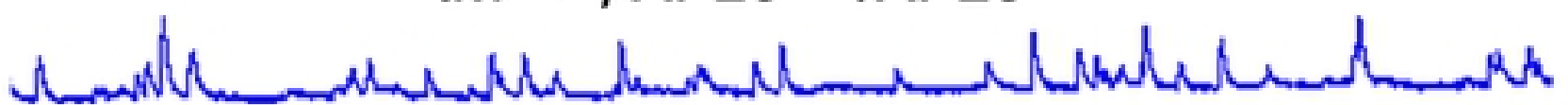
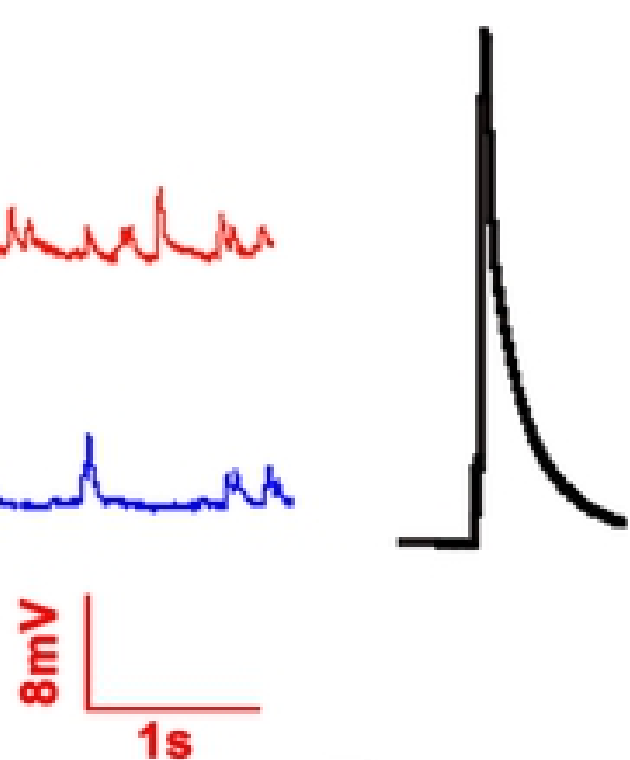

C

\section{Control}

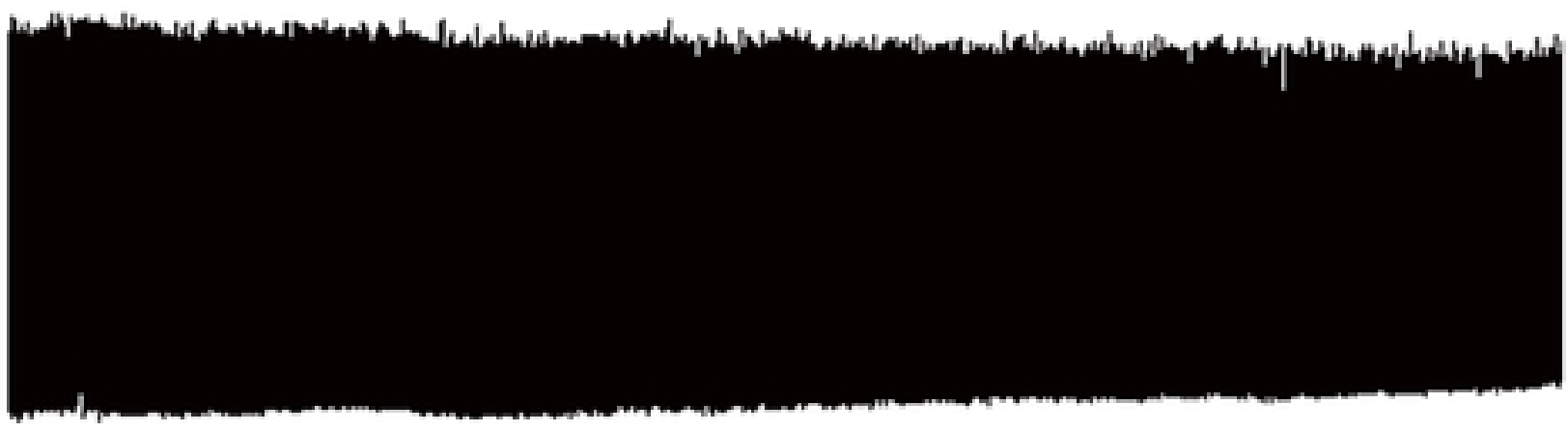

$A P 2 \sigma-{ }^{K G} / A P 2 \sigma-^{a n g} 7$

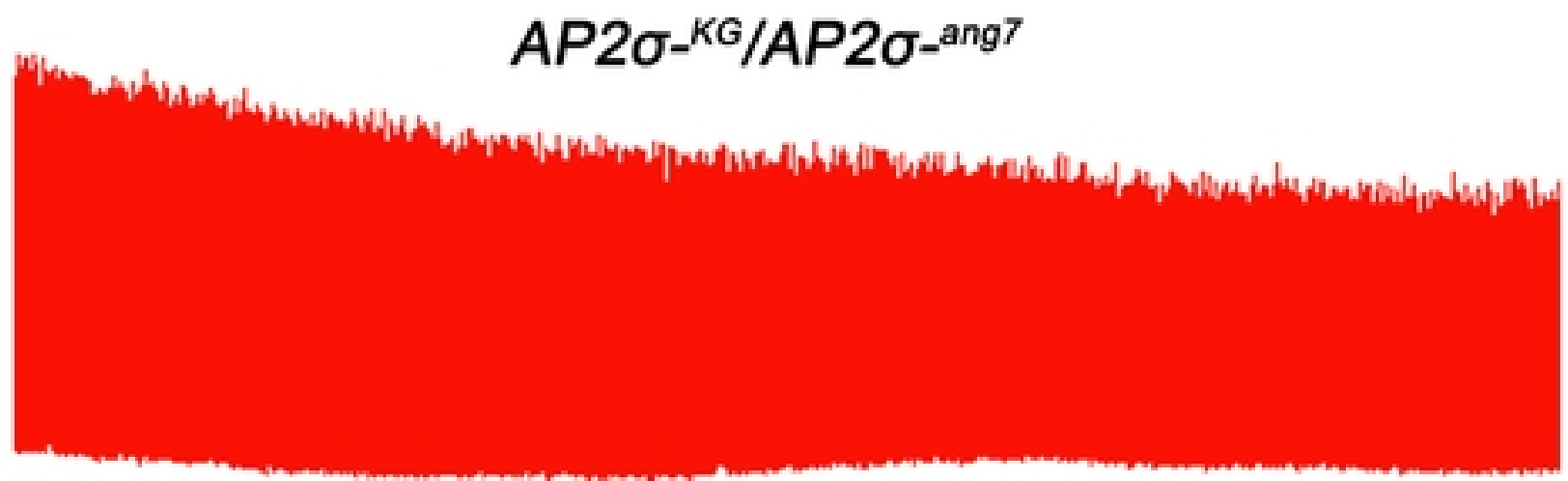

$t k v^{7 /+} ; A P 2 \sigma_{-}{ }^{K G} / A P 2 \sigma$-ang $^{\text {an }}$

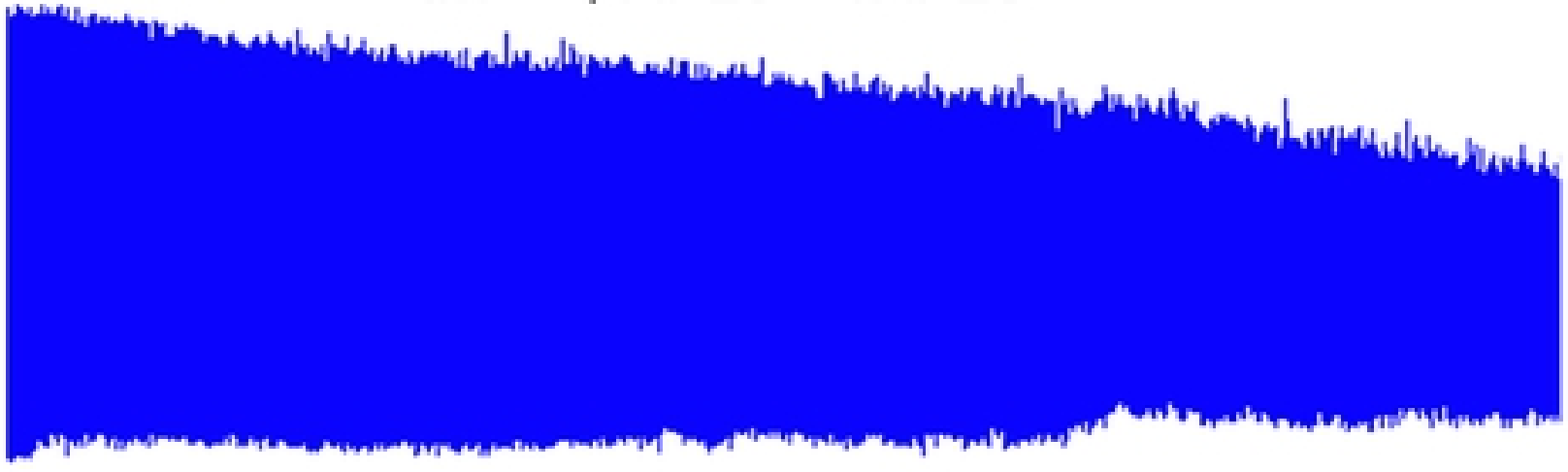

D

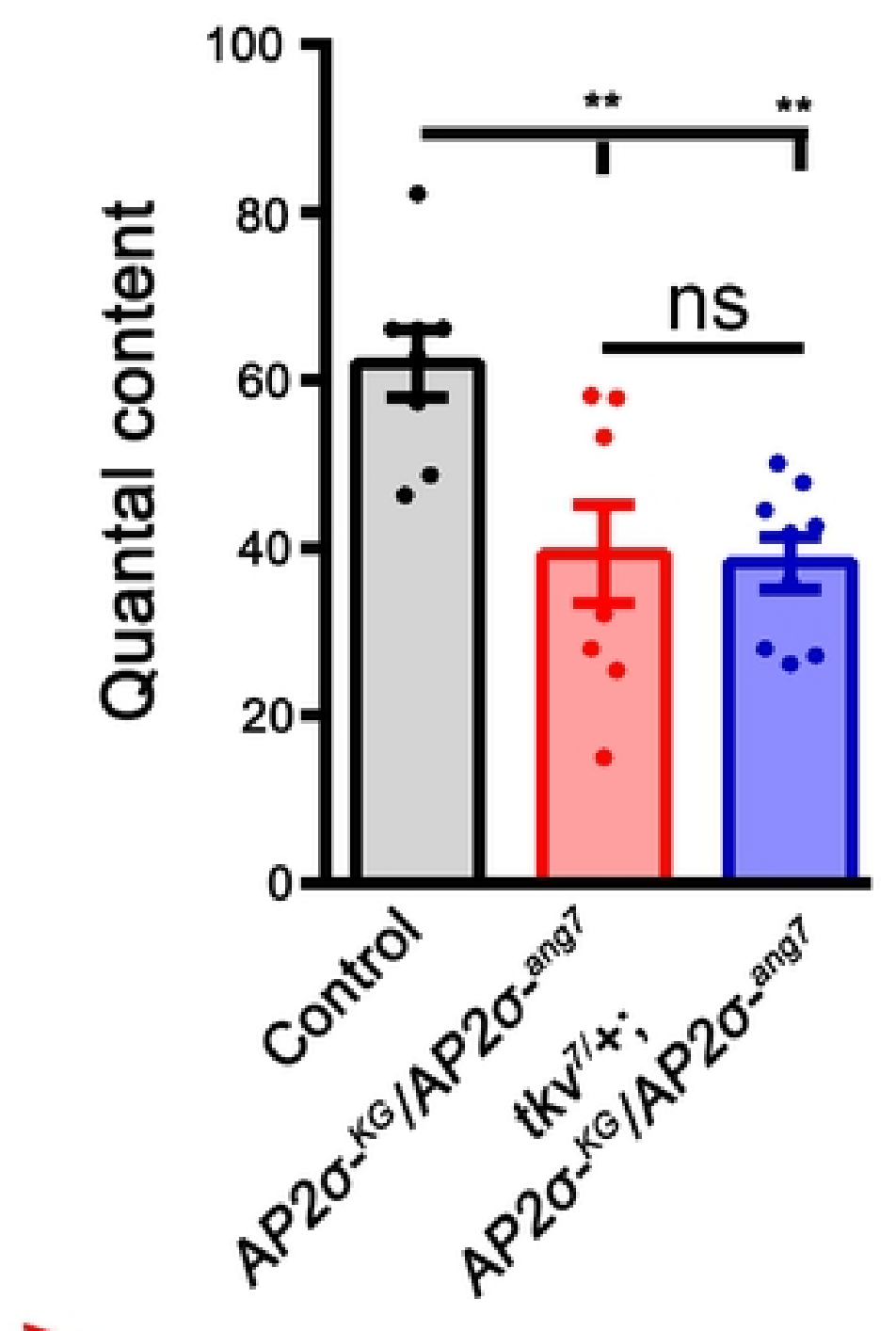

Figure_3

Figure_3 

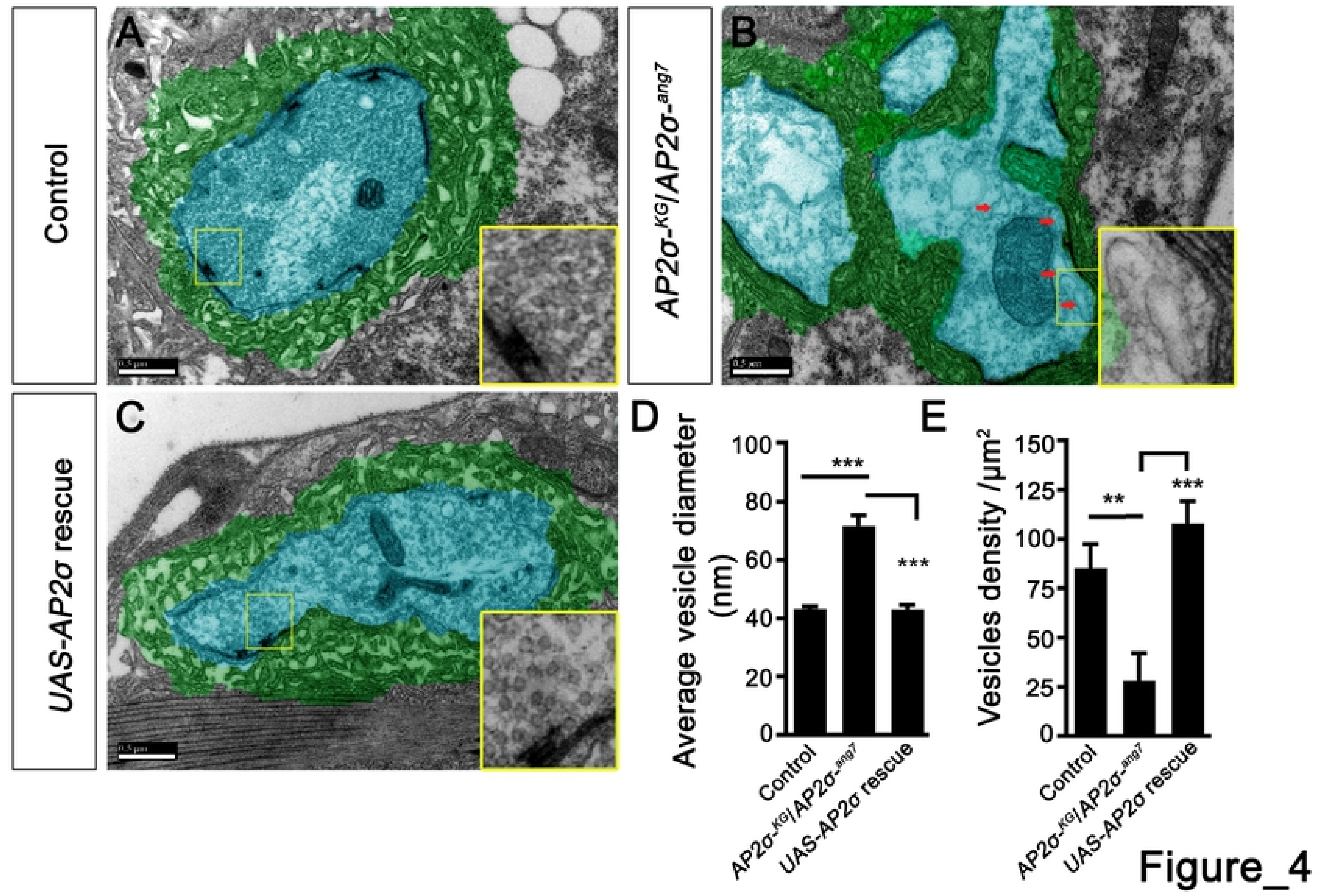

Figure_4 

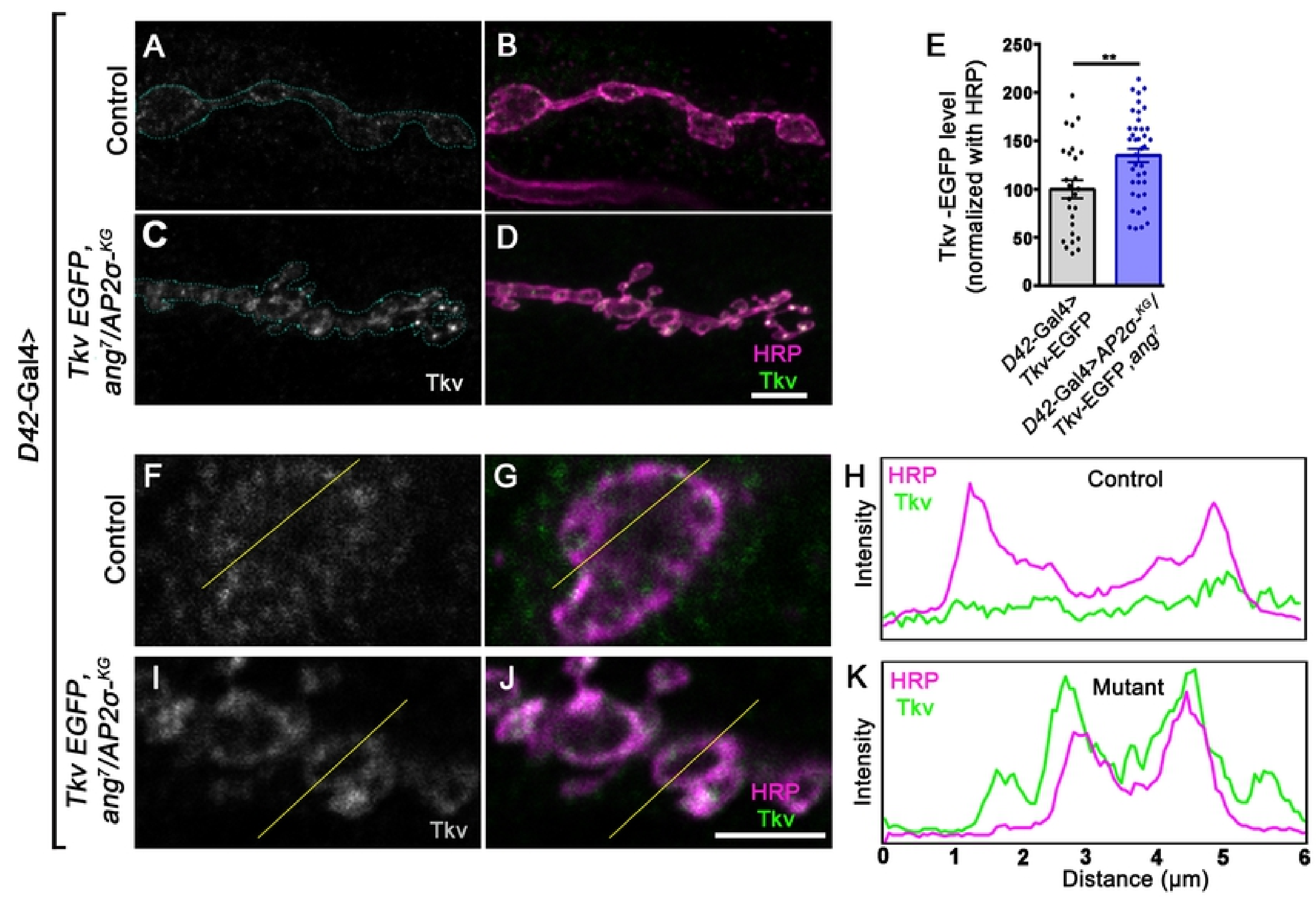

Figure_5

Figure_5 

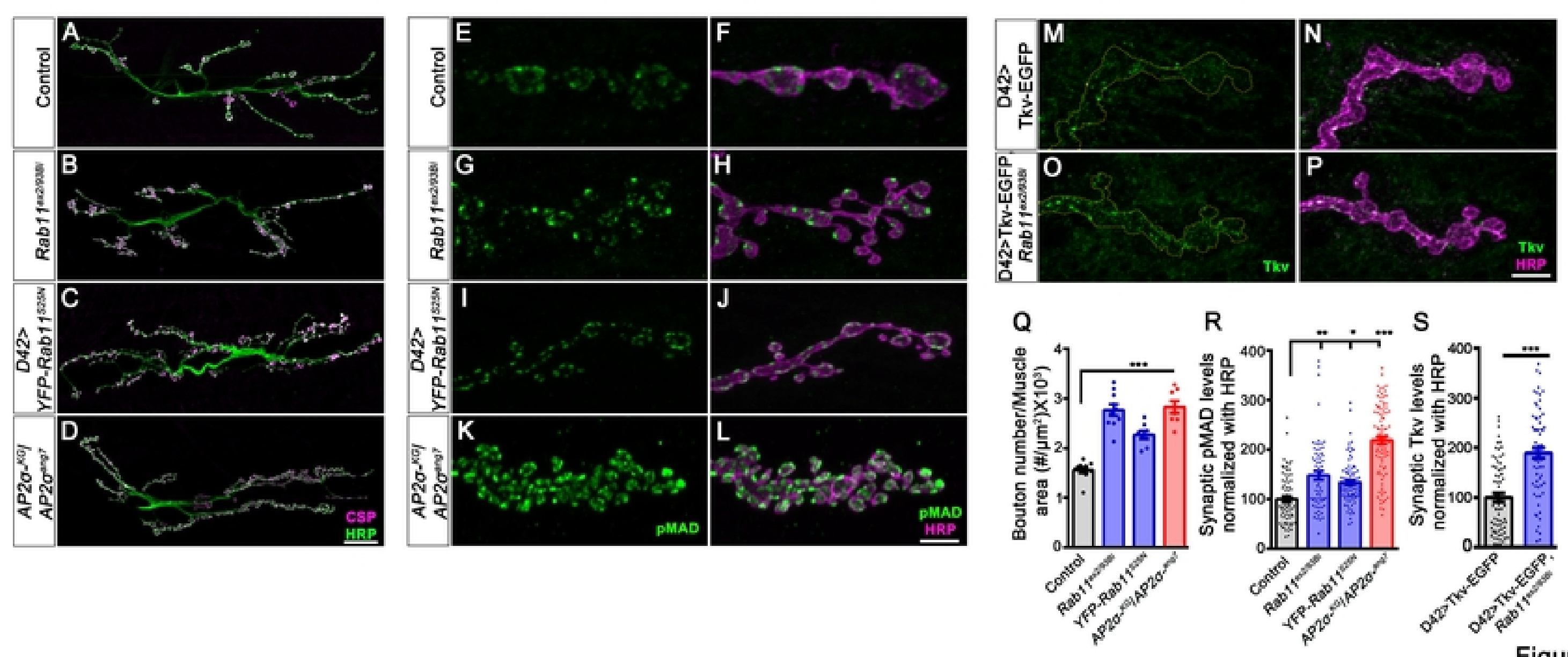

Figure_8

Figure_8 


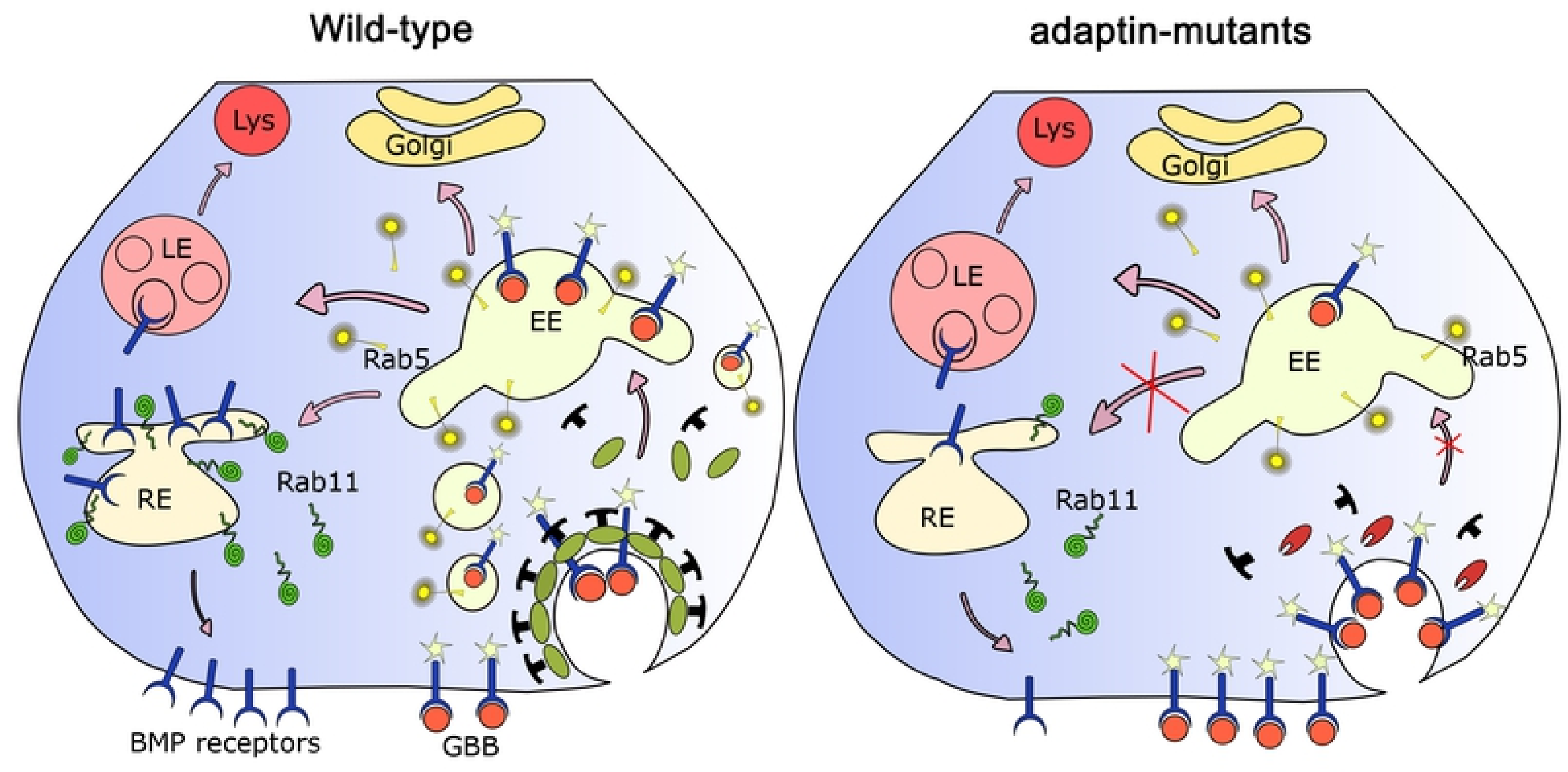

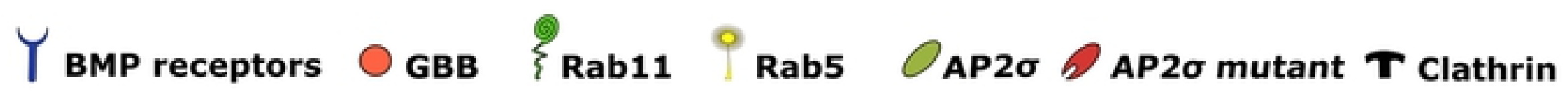

Figure_9

Figure_9 